\title{
A LEGALIDADE E A ÉTICA DE MEDIDAS ESPECIAIS PARA PROTEGER POPULAÇÕES VULNERÁVEIS SOB O DIREITO INTERNACIONAL ${ }^{1}$
}

\author{
Brian D. Lepard \\ Harold W. Conroy Distinguished Professor of Law, University of Nebraska College of Law, \\ Estados Unidos da América.
}

\begin{abstract}
Resumo: Atualmente, em muitos países do mundo, surge uma controvérsia sobre as medidas especiais implementadas por lei para promover o avanço social e econômico de membros de várias populações vulneráveis - medidas muitas vezes chamadas "ações afirmativas". Essas medidas podem tomar a forma de cotas ou de preferências especiais buscando aumentar as oportunidades para membros dessas populações nas áreas de emprego ou educação, por exemplo, ao mesmo nível dos outros membros da sociedade. Esse artigo busca aprofundar as implicações jurídicas e éticas das normas no direito internacional pelas políticas nacionais concernentes às ações afirmativas. Antes de empreender essa exploração, ele revê alguns conceitos da igualdade no nível conceitual. Depois, o artigo explora brevemente a história do tratamento de populações vulneráveis na sociedade e a abordagem adotada pelo direito internacional perante essa história. Ele averigua alguns conceitos fundamentais desenvolvidos no direito internacional contemporâneo relacionados à adoção de medidas especiais para proteger populações vulneráveis. Ao mesmo tempo, o artigo identifica algumas questões que não são resolvidas pelo direito internacional de acordo com uma interpretação tradicional. Em seguida, o artigo elabora uma teoria jurídica e ética sobre como interpretar essas normas do direito internacional e resolver essas questões restantes. Essa teoria é baseada no conceito de "unidade em diversidade", que encontra apoio no direito internacional contemporâneo, bem como nas escrituras reverenciadas de muitas religiões e crenças mundiais. Finalmente, o artigo aplica essa teoria para alcançar algumas conclusões sobre a legalidade e a ética sob o direito internacional de medidas nacionais visando à proteção de populações vulneráveis. 0 artigo não pretende resolver a polêmica existente ao redor deste assunto, mas a esperança é que a abordagem que ele propõe possa nos ajudar a alcançar uma compreensão mais profunda do problema.
\end{abstract}

Palavras-chave: Populações vulneráveis. Medidas especiais. Ações afirmativas. Minorias raciais. Mulheres. Direito internacional. Igualdade. Ética. Escrituras religiosas.

Sumário: Introdução - $\mathbf{1}$ Conceitos importantes de igualdade $\mathbf{- 2} 0$ polêmico sobre ações afirmativas sob a luz destes conceitos - $\mathbf{3} \mathrm{A}$ história do tratamento de populações vulneráveis sob a luz destes conceitos - 4 A evolução da abordagem adotada pelo direito internacional ao tratamento de populações vulneráveis - $5 \mathrm{~A}$ abordagem geral destas fontes de direito internacional à legalidade e à ética de

10 texto se refere à exposição proferida no dia 12.8.2019, no âmbito do XVI Seminário Internacional de Direitos Fundamentais - Políticas Orientadas para a Igualdade e Ações Afirmativas no Direito Internacional, no Direito Comparado e no Brasil, realizado na PUCRS. O evento contou com apoio da Coordenação de Aperfeiçoamento de Pessoal de Nível Superior - Brasil (Capes) - Código de Financiamento 001. 
medidas especiais para proteger populações vulneráveis - 6 Questões restantes - 7 Para uma nova teoria sobre a legalidade e a ética de medidas especiais para proteger os direitos de populações vulneráveis sob o direito internacional - Conclusão - Referências

\section{Introdução}

Atualmente, em muitos países do mundo, surge uma controvérsia sobre as medidas especiais implementadas por lei para promover o avanço social e econômico de membros de várias populações vulneráveis - medidas muitas vezes chamadas "ações afirmativas". Estas medidas podem tomar a forma de cotas ou de preferências especiais buscando aumentar as oportunidades para membros destas populações nas áreas de emprego ou educação, por exemplo, ao mesmo plano do que os outros membros de sociedade.

Um relatório preparado pelas Nações Unidas definiu o termo "ação afirmativa" na maneira seguinte: "A ação afirmativa é um paquete coerente de medidas, de um caráter temporário, visando especificamente a corrigir a posição de membros de um grupo alvo em um ou mais aspectos da sua vida social, a fim de obter igualdade efetiva". ${ }^{2} \mathrm{Um}$ pouco mais tarde terei a oportunidade de averiguar os elementos diferentes desta definição.

Neste capítulo gostaria de aprofundar as implicações jurídicas e éticas das normas no direito internacional pelas políticas nacionais concernentes às ações afirmativas segundo esta definição. Antes de empreender esta exploração, vou rever alguns conceitos da igualdade no nível conceitual. Depois, vou explorar brevemente a história do tratamento de populações vulneráveis na sociedade e a abordagem adotada pelo direito internacional perante esta história. Averiguarei alguns conceitos fundamentais desenvolvidos no direito internacional contemporâneo relacionados à adoção de medidas especiais para proteger populações vulneráveis. Ao mesmo tempo, identificarei algumas questões que não são resolvidas pelo direito internacional de acordo com uma interpretação tradicional. Em seguida, elaborarei uma teoria jurídica e ética sobre como interpretar estas normas do direito internacional e resolver estas questões restantes. Esta teoria é baseada no conceito de "unidade em diversidade", que encontra apoio no direito internacional

\footnotetext{
"A Prevenção da Discriminação: O Conceito e a Prática de Ação Afirmativa: Relatório Final Submetido por Mr. Marc Bossuyt, Repórter Especial, de Acordo com a Resolução 1998/5 da Subcomissão" U.N. Doc. E/CN.4/Sub.2/2002/21 (17 de junho de 2002), para. 6 (citado abaixo como "Relatório do Repórter Especial") (tradução do autor) (UNITED NATIONS. Prevention of Discrimination - The Concept and Practice of Affirmative Action (Final report). E/CN.4/Sub.2/2002/21. Commission on Human Rights, 17 June 2002).
} 
contemporâneo bem como nas escrituras reverenciadas de muitas religiões e crenças mundiais. Finalmente, vou aplicar esta teoria para alcançar algumas conclusões sobre a legalidade e a ética sob o direito internacional de medidas nacionais visando à proteção de populações vulneráveis. Não pretendo que esta abordagem resolva o polêmico que acirra ao redor deste assunto, mas espero que ela possa nos ajudar a alcançar uma compreensão mais profunda do problema.

\section{Conceitos importantes de igualdade}

Primeiro, cabe identificar alguns conceitos rivais da igualdade. O conceito mais comum é da igualdade perante a lei. Conforme este conceito, todas as pessoas são iguais perante a lei e devem ser tratadas pelo governo da mesma forma. Todos têm os mesmos direitos jurídicos. Por exemplo, todos têm o direito à vida e a procedimentos penais justos. Ademais, segundo este conceito, todos os cidadãos têm os mesmos direitos econômicos, sociais e culturais em relação ao governo. Isso quer dizer, por exemplo, que segundo a lei todos podem buscar o emprego, e todos têm o mesmo acesso a programas governamentais de segurança social.

Este conceito de igualdade é formal; ele se concentra no tratamento de pessoas segundo a lei e pelo governo, e geralmente não se concerna com o tratamento de pessoas por outras pessoas e mesmo com os efeitos sobre grupamentos diferentes de pessoas do tratamento "igual" pelo governo. Por exemplo, a lei pode dar a todo o mundo o direito a ser julgado por um juiz que age com autonomia. Mas pode ser que um juiz tenha preconceitos quanto a populações particulares, que influenciam os seus julgamentos de uma maneira subtil. Formalmente, membros destas populações gozam dos mesmos direitos que de outras, mas de fato eles não os desfrutam igualmente. Pode ser também que a lei prescreva que todos possam buscar um emprego. No entanto, por causa de preconceitos, muitos empregadores recuam na contratação de membros de minorias. Para citar um outro exemplo, um programa governamental de segurança social pode dar a todo mundo o mesmo montante anual. Mas por causa de diferenças de renda de cada pessoa, algumas pessoas continuam pobres mesmo com o auxílio, não tendo o suficiente para viver, enquanto outras pessoas ricas poderiam se beneficiar do auxílio do governo para fazer compras de bens luxos. Então o resultado da política "igual” do governo é perpetuar desigualdades de renda ou de riqueza.

Portanto, nós podemos identificar um outro conceito de igualdade, que coloca a ênfase sobre os fatos e não somente a lei, e que visa a alcançar certo nível 
de igualdade de fato entre as pessoas, particularmente relacionada a membros de populações vítimas de discriminação histórica. Pode-se chamar este conceito "igualdade de fato". Mesmo assim, podem existir diferenças nos "fatos" que são enfatizados. Segundo uma versão de igualdade de fato, é importante dar a todo mundo, e especialmente a membros de populações vulneráveis, as oportunidades de conseguir o sucesso, mesmo que alguns não escolhem se beneficiar destas oportunidades e, portanto, não alcancem o mesmo nível econômico ou social de outros. Nós podemos chamar esta abordagem de "igualdade de oportunidade". Por exemplo, o governo pode assegurar que todas as crianças comecem a vida com a mesma qualidade de educação.

Do outro lado, uma segunda versão de igualdade de fato coloca a ênfase sobre os resultados de políticas do governo e mira alcançar um nível de igualdade - por exemplo, econômica - entre as pessoas. Nós podemos chamar esta versão "igualdade de resultado". Neste sentido, o governo poderia agir para fazer com que todos tenham ao menos um nível mínimo parecido de renda, dando auxílio a pessoas que ganham uma renda abaixo deste nível.

Cabe ressaltar, conforme estes exemplos, que conceitos de "igualdade de fato" podem ser implementados por leis adotadas pelo governo. Portanto, a lei pode ser utilizada para efetuar conceitos de igualdade que correm longe além da "igualdade perante a lei". Por exemplo, a lei pode mandar que empresas deem preferências a membros de grupos minoritários. Sob uma ótica, este tipo de medida pode ser visto como um método para alcançar igualdade de resultado. Mas sob uma outra ótica, pode ser visto como um método para assegurar igualdade de oportunidade, tendo em vista a falta de igualdade na educação anterior. Normalmente, nós chamamos os esforços visando à igualdade de resultado de "ações afirmativas", mas nós podemos considerar qualquer medida jurídica uma ação afirmativa se ela visar, além da igualdade perante a lei, a igualdade de fato, seja ela igualdade de oportunidade ou igualdade de resultado.

\section{0 polêmico sobre ações afirmativas sob a luz destes conceitos}

O polêmico sobre ações afirmativas tem similaridades com aquele sobre a pergunta "qual é a justiça?". Ao respeito, o filosofo alemão Hans Kelsen afirmou:

Qual é a justiça? [...] Nenhuma outra pergunta tem sido discutida tão apaixonadamente; nenhuma outra questão tem causado tanto sangue preciosa e tantas lagrimas amargas a ser derramadas; nenhuma 
outra questão tem sido o objeto de tanto pensamento intensivo por parte dos pensadores mais ilustres de Plato até Kant; e contudo, esta questão hoje em dia é tanto não-respondida quanto ela sempre foi. Parece que ela é uma das perguntas a qual a sabedoria resignada aplica que a humanidade não possa encontrar uma resposta definitiva, mas apenas possa tentar de melhorar a pergunta. ${ }^{3}$

Apesar dos problemas parecidos ao definir a igualdade, a compreensão que eu acabei de delinear de conceitos de igualdade pode iluminar as raízes do polêmico contemporâneo quanto às ações afirmativas. Primeiro, sem dúvida existem pessoas que se opõem mesmo à igualdade perante a lei, e que querem que as leis favoreçam populações particulares, por exemplo, brancos de origens europeias. Isso foi o caso dos Estados Unidos durante a época da segregação, quando a discriminação por raça foi institucionalizada por lei nos estados do sul.

No entanto, mesmo quando a igualdade perante a lei é em princípio aceita, disputas podem surgir relacionadas a se este tipo de igualdade é suficiente, ou se outras medidas são necessárias para alcançar igualdade de fato. Algumas pessoas acham que não pode ser uma função apropriada da lei criar igualdade de fato; a lei deve ser limitada a tratar todo mundo da mesma maneira. Outros acreditam que a lei deve promover a igualdade de fato e, portanto, autorizar ou mandar ações específicas para alancar este tipo de igualdade. Mesmo assim os proponentes de tais ações podem disputar sobre como conseguir obter igualdade de fato; por exemplo, deve o propósito ser igualdade de oportunidade, ou igualdade de resultados? E quanto ao primeiro, como medir igualdade de oportunidade? Quanto à igualdade de resultados, pessoas podem adotar perspectivas diferentes sobre os resultados apropriados a buscar. Finalmente, as disputas podem ser acirradas por desacordos sobre as medidas a empreender para obter igualdade de oportunidade ou de resultados. Por exemplo, é apropriado mandar medidas por lei? Ou seria preferível usar incentivos voluntários, tais como incentivos financeiros, para promover medidas especiais?

Com certeza, estas disputas têm dimensões éticas importantes. De uma ótica, qualquer tipo de preferência por uma pessoa acima de uma outra pode ser percebido como uma violação do princípio de igualdade perante a lei. De outra, contudo, as preferências são necessárias para alcançar igualdade de fato em um mundo histórico e atual no qual as minorias têm sofrido e continuam a sofrer discriminação de fato.

3 KELSEN, Hans. What is Justice? Justice, Law and Politics in the Mirror of Science. Berkeley and Los Angeles: University of California Press, 1957. p. 1. 
O papel do valor de diversidade ao justificar medidas especiais no nível da ética é também muito controvertido. Nos olhos de muitos observadores, este valor pode suportar tais medidas mesmo se ele parece violar qualquer conceito de igualdade. Estes proponentes podem adotar o ponto de vista que "um ambiente racialmente e etnicamente diverso reflete a sociedade mais larga e promove um senso de comunidade mais representativo enriquecido". ${ }^{4}$ No entanto, do outro lado, outros argumentam que a busca da diversidade não pode justificar partidas do princípio de igualdade de alguma forma.

Ademais, com certeza estes debates levantam questões jurídicas críticas, tais como se o princípio de igualdade perante a lei pode tolerar tais preferências especiais, ou se tais preferências constituem uma violação deste princípio básico da ordem jurídica democrática. Igualmente disputas podem surgir, novamente, sobre a legitimidade de considerar a promoção de diversidade como justificativa jurídica por medidas especiais. Neste respeito, a Corte Suprema dos Estados Unidos apoiou este valor no caso de Regents of the University of California v. Bakke, ${ }^{5}$ envolvendo ações afirmativas no campo de educação universitária. Neste caso, a Corte disse que uma meta legítima da universidade foi aquela de criar um corpo estudantil diverso para trazer perspectivas diferentes à aula. ${ }^{6}$ Contudo, esta visão da Corte atualmente é controvertida.

Um especialista nos Estados Unidos resumiu o debate entre os oponentes de ações afirmativas e suas proponentes na maneira seguinte:

A Direita nos tem dito a resistir ação afirmativa porque ela não é meritocrática, resulta em discriminação reversa, e constitui uma garantia não americana de resultados iguais em vez de oportunidade igual. A Esquerda nos tem dito a apoiá-la como compensação por injustiças passadas, uma garantia de um pedaço justo da tarte econômica, e porque ela é um direito civil, garantido pela Constituição e refinado por estatutos posteriores. ${ }^{7}$

\footnotetext{
Relatório do Repórter Especial, para. 20.

5 ESTADOS UNIDOS DA AMÉRICA. Suprema Corte dos Estados Unidos. Regents of the Univ. of Calif. v. Bakke, 438 U.S. 265. Decidido em 28.06.1978.

6 A Corte declarou: “A atmosfera de 'especulação, experimento e criação' - tão essencial à qualidade de educação superior - é largamente acreditada ser promovida por um corpo estudantil diversificado [...]. [A] nossa tradição e experiência prestam apoio à visão de que a contribuição de diversidade é substancial" (ESTADOS UNIDOS DA AMÉRICA. Suprema Corte dos Estados Unidos. Regents of the Univ. of Calif. v. Bakke, 438 U.S. 265. Decidido em 28.06.1978. p. 312-13) (tradução do autor).

7 SKRENTNY, John David. The Ironies of Affirmative Action: Politics, Culture, and Justice in America. Chicago \& London: The University of Chicago Press, 1996. p. 1 (tradução do autor).
} 
Por causa destas questões controvertidas tanto jurídicas quanto éticas, existem muitas discussões e muitos desacordos sobre o uso de ações afirmativas. É muito difícil saber como resolver estes desacordos sem uma visão comum e sofisticada destes problemas. Em breve vou apurar o papel do direito internacional em traçando uma tal visão. Mas primeiro é instrutivo rever a história do tratamento de populações vulneráveis e da adoção de medidas jurídicas motivadas por estes conceitos diferentes de igualdade.

\section{A história do tratamento de populações vulneráveis sob a luz destes conceitos}

Não é necessário recordar aqui a história triste da opressão de muitas populações através da história humana. Basta notar que, na maioria das sociedades, não só as normas sociais, religiosas e morais como também a lei discriminaram abertamente populações específicas - servos, populações indígenas, estrangeiros, imigrantes, negros, membros de minorias religiosas, mulheres, homossexuais, entre outros. A prática da escravidão foi particularmente odiosa. Contudo, ela persistia durante milênios, e foi proibida por lei somente durante os dois séculos passados.

De fato, antes das eras de "renascimento" e "iluminação" em muitas sociedades, inclusive no Ocidente, as leis locais, regionais e nacionais discriminaram explicitamente muitas populações. A ideia de que a lei deve reconhecer a igualdade de todas pessoas foi uma inovação ética importante, sendo a ideia inspiradora de algumas revoluções no Oeste durante o século XVIII, notavelmente a Revolução Americana e a Revolução Francesa. Por exemplo, a Declaração de Independência dos Estados Unidos, esboçada em 1776, afirmou que "Nós acreditamos estas verdades ser evidentes em si, que todos os homens são criados iguais, que eles são dotados por seu Criador com direitos certos inalienáveis, que entre eles são a vida, a liberdade, e a perseguição da felicidade". ${ }^{8}$ Ao mesmo sentido, a Declaração francesa dos Direitos do Homem e do Cidadão de 1789 sustentou que "Os homens nascem e são livres e iguais em direitos. As distinções sociais só podem fundar-se na utilidade comum". ${ }^{9}$ E esta Declaração sustenta o princípio de igualdade perante a lei no seu Artigo 6, afirmando que a lei:

8 OS TREZE ESTADOS UNIDOS DA AMÉRICA. Declaração de Independência dos Estados Unidos, 04 de julho de 1776. Disponível em: https://www.archives.gov/founding-docs/declaration-transcript. Acesso em: 29 maio 2020. (tradução do autor).

9 ASSEMBLEIA NACIONAL CONSTITUINTE FRANCESA. Declaração dos Direitos do Homem e do Cidadão de 1789. Disponível em: http://pfdc.pgr.mpf.mp.br/atuacao-e-conteudos-de-apoio/legislacao/direitoshumanos/declar_dir_homem_cidadao.pdf. Acesso em: 29 maio 2020. Art. 1. 
deve ser a mesma para todos, quer se destine a proteger quer a punir. Todos os cidadãos são iguais a seus olhos, são igualmente admissíveis a todas as dignidades, lugares e empregos públicos, segundo a sua capacidade, e sem outra distinção que não seja a das suas virtudes e dos seus talentos. ${ }^{10}$

Esta visão parece admitir distinções entre pessoas apenas na base de talentos e capacidades, e não por ser membro de um grupo certo.

Apesar destas afirmações da igualdade perante a lei, as visões dos redatores destes documentos influentes foram manchadas por preconceitos enraizados que perpetuavam discriminação contra grupamentos particulares. Por exemplo, a Constituição dos Estados Unidos não conferiu direitos humanos aos escravos negros, e na computação do número de representantes no Congresso federal de cada Estado ela permitiu que cada escravo fosse contado apenas como $3 / 5$ de uma pessoa - efetivamente deprimindo o escravo do direito de ser reconhecido como um ser humano completo. ${ }^{11}$

Nos sistemas de lei religiosos também apareceram as mesmas tendências a justificar a opressão de populações particulares. Por exemplo, a maioria das leis religiosas dá um lugar privilegiado aos homens. Muitas entre elas aceitaram a instituição da escravidão, mesmo se elas buscaram moderar os efeitos mais horríficos da prática. Foi comum também nestes sistemas de lei religiosa desfavorecer não aderentes, ou mesmo justificar "guerras santas" contra eles.

Ao longo dos duzentos anos passados, nós vimos nos sistemas de lei nacionais um reconhecimento da injustiça do tratamento histórico de várias categorias de populações vulneráveis, resultando na aceitação e divulgação do conceito de igualdade perante a lei. Por exemplo, nos Estados Unidos, a Guerra Civil de 1861-1865 resultou na adoção de emendas à Constituição americana proibindo qualquer discriminação, incluindo na base na raça. Particularmente, a Emenda XIII declara, simplesmente, que “nem a escravidão nem a servidão involuntária, exceto como punição por um crime de qual o partido tenha sido

10 ASSEMBLEIA NACIONAL CONSTITUINTE FRANCESA. Declaração dos Direitos do Homem e do Cidadão de 1789. Disponível em: http://pfdc.pgr.mpf.mp.br/atuacao-e-conteudos-de-apoio/legislacao/direitoshumanos/declar_dir_homem_cidadao.pdf. Acesso em: 29 maio 2020. Art. 6.

11 Ao respeito, o Artigo 1, seção 2, cláusula 3 da Constituição afirmou: "Representantes e tributos diretos devem ser repartidos entre os Estados vários que podem ser incluídos nesta União, de acordo com os seus números respetivos, que devem ser determinados ao somar ao número inteiro de pessoas livres, incluindo aquelas obrigadas a server por um prazo de anos, e excluindo índios não tributados, três-quintos de todas outras pessoas [ou seja, escravos]" (tradução do autor). 
devidamente condenado, deve existir dentro dos Estados Unidos, ou em lugar algum sujeito a sua jurisdição". ${ }^{12} \mathrm{~A}$ Emenda XIV afirma:

todas as pessoas nascidas ou naturalizadas nos Estados Unidos [...] são cidadãos dos Estados Unidos e do Estado no qual elas residem. Nenhum Estado deve fazer ou enforcar qualquer lei que abrevia os privilégios ou imunidades de cidadãos dos Estados Unidos; nem deve Estado algum privar qualquer pessoa da vida, da liberdade, ou da propriedade, sem o processo devido de lei; nem negar a qualquer pessoa dentro da sua jurisdição a proteção igual das leis. ${ }^{13}$

A disposição também insiste que toda pessoa, exceto os índios não tributados, seja contada como uma pessoa inteira pelo propósito das eleições para a Câmara de Deputados. ${ }^{14}$ Segundo a Emenda XV, "o direito de cidadãos dos Estados Unidos a votar não será negado ou abreviado pelos Estados Unidos ou por Estado algum por motivo de raça, cor, ou condição anterior de servidão". ${ }^{15}$

É comum para muitas constituições nacionais contemporâneas afirmar a igualdade completa de todos os cidadãos perante a lei. Por exemplo, a Constituição Federativa do Brasil de 1988 afirma no seu art. 5ำ que "Todos são iguais perante a lei, sem distinção de qualquer natureza, garantindo-se aos brasileiros e aos estrangeiros residentes no País a inviolabilidade do direito à vida, à liberdade, à igualdade, à segurança e à propriedade". ${ }^{16}$ Pelas populações vulneráveis, foi uma vitória marcante poder se beneficiar, afinal, de tais afirmações da sua igualdade com os seus concidadãos.

No entanto, muitas constituições têm ido além de uma tal afirmação de igualdade perante a lei, reconhecendo que este tipo de disposição não pode ser suficiente para eliminar séculos de discriminação contra populações desfavorecidas. Portanto, muitas constituições contemporâneas dão reconhecimento explícito a categorias particulares de populações e buscam assegurar que elas possam gozar de direitos particulares em um patamar de igualdade.

12 ESTADOS UNIDOS DA AMÉRICA. Constituição dos Estados Unidos. Disponível em: https://www.archives. gov/founding-docs/constitution. Acesso em: 29 maio 2020. Emenda XIII, sec. 1 (tradução do autor).

13 ESTADOS UNIDOS DA AMÉRICA. Constituição dos Estados Unidos. Disponível em: https://www.archives. gov/founding-docs/constitution. Acesso em: 29 maio 2020. Emenda XIV, sec. 1 (tradução do autor).

14 ESTADOS UNIDOS DA AMÉRICA. Constituição dos Estados Unidos. Disponível em: https://www.archives. gov/founding-docs/constitution. Acesso em: 29 maio 2020. Emenda XIV, sec. 2.

15 ESTADOS UNIDOS DA AMÉRICA. Constituição dos Estados Unidos. Disponível em: https://www.archives. gov/founding-docs/constitution. Acesso em: 29 maio 2020. Emenda XV (tradução do autor).

16 BRASIL. Constituição da República Federativa do Brasil de 1988. Brasília, 1988. Disponível em: http:// www.planalto.gov.br/ccivil_03/Constituicao/Constituicao.htm. Acesso em: 29 maio 2020. Art. 5. 
Por exemplo, a Constituição da Índia de 1948 afirma geralmente que "O Estado não negará a pessoa alguma a igualdade perante a lei ou a proteção igual das leis dentro do território de Índia". ${ }^{17}$ Ademais, ela diz que "O Estado não discriminará contra cidadão algum em razão de religião, raça, casta, sexo, lugar de nascimento, ou alguma delas". ${ }^{18}$ Ao mesmo tempo a Constituição afirma que nada na disposição precedente "impedirá o Estado ao fazer provisão especial alguma para o avançamento de quaisquer classes de cidadãos socialmente ou educacionalmente desfavorecidos ou para as castas especificadas ou para as tribos especificadas". ${ }^{19} \mathrm{E}$ a Constituição permite que o governo possa reservar vagas nos serviços do Estado em prol de classes desfavorecidas ou de castas e tribos específicas que não são representadas o suficiente nos serviços do Estado. $^{20}$

Muitas nações têm adotado medidas legislativas e administravas para avançar o bem-estar de grupos particulares. Não é possível aqui rever estas leis. No entanto, para oferecer um exemplo relevante aos Estados Unidos, o país adotou algumas leis importantes promovendo o avanço de pessoas negras durante a era de "direitos civis" na década de 1960. O então Presidente Lyndon Johnson proclamou: "Nós buscamos [...] não somente igualdade como um direito e uma teoria, mas igualdade como um fato e igualdade como um resultado", invocando conceitos que eu já elaborei acima. ${ }^{21} \mathrm{Um}$ produto do movimento em prol de direitos civis foi a adoção do Título VII do Ato de Direitos Civis de 1964, que proibiu a discriminação em empregos. Eventualmente a Corte Suprema dos Estados Unidos decidiu que a lei proibiu não somente discriminação aberta, mas sim práticas justas em forma mas discriminatórias em operação", significando práticas que têm um "impacto desigual" sobre membros de grupos minoritários ou mulheres. ${ }^{22}$

As medidas legislativas e administrativas adotadas nos Estados Unidos incluíram uma obrigação por parte de todas as empresas contratando com o

17 ÍNDIA. Constituição da Índia. Disponível em: https://www.india.gov.in/sites/upload_files/npi/files/coi_ part_full.pdf. Acesso em: 29 maio 2020. Art. 14 (tradução do autor).

18 ÍNDIA. Constituição da Índia. Disponível em: https://www.india.gov.in/sites/upload_files/npi/files/coi_ part_full.pdf. Acesso em: 29 maio 2020. Art. 15, para. 1 (tradução do autor).

19 ÍNDIA. Constituição da Índia. Disponível em: https://www.india.gov.in/sites/upload_files/npi/files/coi_ part_full.pdf. Acesso em: 29 maio 2020. Art. 15, para. 4 (tradução do autor).

20 Veja ÍNDIA. Constituição da Índia. Disponível em: https://www.india.gov.in/sites/upload_files/npi/files/ coi_part_full.pdf. Acesso em: 29 maio 2020. Art. 16, para. 4, 4A (tradução do autor).

21 Extraído da Palestra do Presidente Johnson aos alunos da Universidade de Howard, em junho de 1965, citado em CAHN, Steven M. (Ed.). The Affirmative Action Debate. London: Routledge, 1995. p. xii, citado em Relatório do Repórter Especial, p. 27 n. 11 (tradução do autor).

22 GINSBERG, Ruth Bader. Remarks on the Value of Diversity: International Affirmative Action. Institut d'Etudes Politiques, Paris, France, 17 de julho de 2009. In: GINSBERG, Ruth Bader; HARTNETT, Mary; WILLIAMS, Wendy W. My Own Words. New York: Simon \& Schuster, 2016. p. 271 (tradução do autor). 
Governo federal de empregar mulheres e minorias raciais e étnicas. ${ }^{23}$ Por exemplo, o site do Departamento de Trabalho diz o seguinte:

Para empreiteiros e subempreiteiros federais, ação afirmativa deve ser tomada por empregadores cobertos a recrutar e avançar minorias qualificadas, mulheres, pessoas com deficiências, e veteranos cobertos. Ações afirmativas incluem programas de treinamento, esforços de divulgação, e outros passos positivos. ${ }^{24}$

No entanto, em décadas recentes a Corte Suprema tem invalidado algumas medidas especiais, especialmente aquelas que parecem ser cotas ou preferências fixas e obrigatórias. ${ }^{25}$

\section{A evolução da abordagem adotada pelo direito internacional ao tratamento de populações vulneráveis}

Agora eu volto à evolução da abordagem adotada pelo direito internacional ao tratamento de populações vulneráveis. 0 direito internacional é criado pelos estados; então ele tem a tendência de seguir as evoluções nas atitudes de estados concernentes às populações vulneráveis. Ao mesmo tempo, ele tem adquirido uma forca especial em si durante os séculos e, portanto, tem tido uma influência importante sobre as políticas dos estados quanto a minorias e outras populações vulneráveis, incluindo ações afirmativas.

Existem duas fontes principais do direito internacional, ambas derivando mais ou menos da vontade de estados soberanos. Estas fontes são identificadas no Estatuto da Corte Internacional de Justiça (CIJ) no seu artigo $38 .{ }^{26}$

A primeira fonte é composta de tratados concluídos entre dois ou mais estados; estes constituem uma forma de contrato escrito. A segunda é o direito internacional consuetudinário, que evolui da união de uma prática consistente

23 Veja GINSBERG, Ruth Bader. Remarks on the Value of Diversity: International Affirmative Action. Institut d'Etudes Politiques, Paris, France, 17 de julho de 2009. In: GINSBERG, Ruth Bader; HARTNETT, Mary; WILLIAMS, Wendy W. My Own Words. New York: Simon \& Schuster, 2016.

24 Veja ESTADOS UNIDOS DA AMÉRICA. Departamento de Trabalho dos Estados Unidos. Ação Afirmativa. Disponível em: https://www.dol.gov/general/topic/hiring/affirmativeact. Acesso em: 29 maio 2020.

25 Veja, por exemplo, a discussão de casos decididos pela Corte Suprema dos Estados Unidas em BECKMAN, James A. Introduction. In: BECKMAN, James A. Controversies in Affirmative Action: Historical Dimensions. Santa Barbara, Ca.: Praeger, 2014. v. 1. p. xxii-xxx.

26 Veja NAÇÕES UNIDAS. Estatuto da Corte Internacional de Justiça. 1945. Disponível em: http://www. direitoshumanos.usp.br/index.php/Corte-Internacional-de-Justi\%C3\%A7a/estatuto-da-corte-internacionalde-justica.html. Acesso em: 29 maio 2020. Art. 38(1)(a), (b). 
entre a maioria dos estados (que pode ser chamada um "costume") e a crença por parte destes estados de que eles são obrigados por lei a seguir esta prática (que se chama opinio juris em latim).

Segundo a doutrina tradicional do direito internacional, quando estados concluem um tratado, eles Ihe dão o seu consentimento explícito; este consentimento justifica a autoridade dos tratados. De outro lado, quando estados participam em uma prática e possuem a crença de que eles são obrigados a fazêla, esta ação e esta crença são indicadores da sua vontade. Esta teoria tradicional de direito internacional foi desenvolvida por teoristas influenciais, mas também com a aprovação de estados eles mesmos. ${ }^{27}$

Tendo em vista estes conceitos, nós podemos constatar que antigamente o direito internacional, e particularmente o direito internacional consuetudinário, ratificou as práticas discriminatórias dos estados perante populações vulneráveis, permitindo que os estados ajam de uma maneira abertamente hostil a estas populações. Por exemplo, o direito internacional consuetudinário permitiu a conquista de territórios indígenas pelos poderes europeus. Nós podemos encontrar um exemplo chocante desta aprovação em uma opinião da Corte Suprema dos Estados Unidos quanto aos índios, em que a Corte declarou, relacionado ao direito do Governo dos Estados Unidos ao título sobres as terras antigamente ocupadas pelos povos indígenas americanos, que "a conquista confere um título que os tribunais do conquistador não podem negar [...]. O título por conquista é adquirido e mantido pela força". ${ }^{28}$

No entanto, o direito internacional pode exercer, às vezes, uma influência moderadora sobre estas políticas. Por exemplo, pensadores como Francisco Suárez (1548-1617), filósofo jurídico católico espanhol, e Hugo Grotius (15831645), que se acredita ter estabelecido o direito internacional em uma base secular, juntos invocaram um "direito natural". De acordo com estes pensadores, o direito natural foi evidenciado por textos religiosos como a Bíblia, e prescreveu que todos os homens são criados por uma força divina e então gozam de uma dignidade inata e devem ser unidos como uma família. Suarez escreveu no seu livro Sobre Leis e Deus como Legislador.

27 Sobre esta doutrina tradicional concernente aos tratados e ao direito internacional consuetudinário, veja LEPARD, Brian D. Customary International Law. A New Theory with Practical Applications. New York: Cambridge University Press, 2010. p. 1-9.

28 ESTADOS UNIDOS DA AMÉRICA. Suprema Corte dos Estados Unidos. Johnson v. M'Intosh, 21 U.S. (8 Wheaton) 543, 588-89. Decidido em 27 e 28.02.1823. Disponivel em: https://supreme.justia.com/ cases/federal/us/21/543/. Acesso em: 29 maio 2020. 
a raça humana, em quaisquer números diferentes de povos e reinos ela possa ser dividida, sempre preserva uma certa unidade, não apenas como uma espécie, mas também uma unidade moral e política (como fosse) ordenada pelo preceito natural de amor mutual e mercê; um preceito que aplica a todos, até aos estrangeiros de toda nação. ${ }^{29}$

Esta concepção, derivando em parte de textos santos, mas elaborada pelo raciocínio humano, apoiou certa moderação nas medidas discriminadoras empreendidas contra populações vulneráveis, incluindo as populações indígenas. Ao mesmo sentido, alguns séculos antes, o pensador espanhol domínico Francisco Vitoria (1480-1546) argumentou que os conquistadores espanhóis tinham que tratar os índios no novo mundo com respeito e humanidade. ${ }^{30}$

A Primeira Guerra Mundial foi acendida por tensões entre os poderes grandes agravadas por disputas sobre minorias nacionais, linguísticas, étnicas, e religiosas em vários países, que muitas vezes tinham ligações com poderes exteriores. Por causa disso o Presidente americano Woodrow Wilson, em anunciando as finalidades da guerra conforme sua visão, articulou "Quatorze Pontos", incluindo o princípio de “autodeterminação”. Por exemplo, o Ponto V defendeu:

Um ajustamento libre, com mente aberta, e absolutamente imparcial de toda reclamação colonial, baseado na observa estrita do princípio que na determinação de todas tais questões de soberania os interesses das populações concernidas devem ter um peso igual às reclamações equáveis do governo o título do qual está a ser determinado. ${ }^{31}$

Existia acordo entre os poderes vitoriosos sobre o papel de disputas sobre o tratamento de minorias como raiz importante da guerra na Conferência de Paris de 1919. Por isso, estes poderes também entraram, ao lado da recém criada Sociedade das Nações, em tratados com os países derrotados, obrigando-os a respeitar os direitos destas minorias.

29 SUÁREZ, Francisco. Selections from Three Works of Francisco Suárez. Tradução de Gwladys L. Williams, Ammi Brown, e John Waldron, com certas revisões por Henry Davis, S.J. Oxford: Clarendon Press; London: Humphrey Milford, 1944. v. 2. p. 348.

30 Veja NUSSBAUM, Arthur. A Concise History of the Law of Nations. New York: The Macmillan Company, 1954. p. 79-80.

31 WILSON, Woodrow. President Woodrow Wilson's Fourteen Points. 8 jan. 1918. Disponível em: https:// avalon.law.yale.edu/20th_century/wilson14.asp. Acesso em: 29 maio 2020 (tradução do autor). 
O primeiro tratado minoritário foi aquele com a Polônia, que buscava proteger os judeus, entre outros grupos minoritários. ${ }^{32}$ As disposições deste tratado e dos outros foram desenhadas para assegurar a igualdade tanto de fato quanto perante a lei destes grupos, e elas podem ser percebidas como estabelecendo "ações afirmativas". Por exemplo, o artigo 8 do tratado com o Polônia declara:

Nacionais poloneses pertencendo a minorias raciais, religiosas ou linguísticas devem beneficiar do mesmo tratamento e segurança de acordo com a lei e de fato que outros nacionais poloneses. Particularmente, eles devem possuir o mesmo direito a estabelecer, gerir e controlar, as suas próprias custas, instituições caridosas, religiosas e sociais, escolas, e outros estabelecimentos educacionais, com o direito de usar a sua própria língua e exercer a sua própria religião livremente nelas. ${ }^{33}$

O artigo 11 afirma em parte que judeus não podem ser forçados a desempenhar ato algum que constitui uma violação ao Sábado judaico.

Estes "tratados sobre minorias" foram supervisionados pela Sociedade, que estabeleceu um sistema extensivo pela proteção das minorias, incluindo medidas permitindo que membros destes grupamentos fizessem reclamações a um comitê especial do Conselho da Sociedade. ${ }^{34}$ Muitos observadores da história do conceito de direitos humanos veem neste sistema uma etapa importante no desenvolvimento da ideia de direitos humanos. Ao lado deste sistema, o Pacto da Sociedade deu atenção à situação lamentável de vítimas de tráfico humano, principalmente mulheres e crianças, e a condições de trabalho nocivos, que feriram muitos trabalhadores pobres. ${ }^{35}$

32 IMPÉRIO BRITÂNICO; FRANÇA; ITÁLIA; JAPÃO; ESTADOS UNIDOS; POLÔNIA. Tratado sobre as minorias entre os poderes principais aliados e associados (o Império britânico, França, Itália, Japão e os Estados Unidos) e Polônia, firmado em Versailles (28 junho 1919). Disponivel em: http://www.forost.ungarischesinstitut.de/pdf/19190628-3.pdf. Acesso em: 29 maio 2020.

33 IMPÉRIO BRITÂNICO; FRANÇA; ITÁLIA; JAPÃO; ESTADOS UNIDOS; POLÔNIA. Tratado sobre as minorias entre os poderes principais aliados e associados (o Império britânico, França, Itália, Japão e os Estados Unidos) e Polônia, firmado em Versailles (28 junho 1919). Disponivel em: http://www.forost.ungarischesinstitut.de/pdf/19190628-3.pdf. Acesso em: 29 maio 2020. Art. 8 (grifos nossos) (tradução do autor).

34 Veja THORNBERRY, Patrick. International Law and the Rights of Minorities. Oxford: Clarendon Press, 1991. p. 38-54.

35 Veja o Pacto da Sociedade das Nações (1919), artigo 23(a), (c) (dando à Sociedade o poder de supervisionar a execução de acordos sobre o tráfico das mulheres e das crianças e dando a todo o mundo o direito a condições de trabalho justas e humanas) (SOCIEDADE DAS NAÇÕES. Pacto da Sociedade das Nações. 1919. Disponivel em: http://dhnet.org.br/direitos/anthist/his1919.htm. Acesso em: 29 maio 2020). 
Durante a vida da Sociedade das Nações, a Corte Permanente de Justiça teve a oportunidade de considerar o significado das disposições dos tratados sobre minorias tratando da igualdade. No caso das Escolas Minoritárias na Albânia, decidido em $1935,{ }^{36}$ a Corte disse:

Igualdade em lei impede discriminação de qualquer tipo; enquanto igualdade de fato pode envolver a necessidade de tratamento diferente ao fim de obter um resultado que estabelece um equilibro entre situações diferentes [...]. A igualdade entre membros da maioria e da minoridade tem que ser uma igualdade efetiva e genuína. ${ }^{37}$

Infelizmente, os esforços da Sociedade nas Nações para melhorar a condição de populações vulneráveis não puderam eliminar os preconceitos contra elas ou o uso destas populações por líderes avaros para criar a animosidade. Líderes como Hitler empreenderam uma campanha contra populações desfavorecidas, incluindo os judeus, desencadeando uma campanha de genocídio e opressão contra elas. Mais de 5 milhões de judeus perderam a vida durante a Segunda Guerra Mundial.

Em grande parte por causa dos sofrimentos destas minorias, a Carta das Nações Unidas, adotada em 1945, afirma que todos os povos das Nações Unidas são resolvidos a "reafirmar a fé nos direitos humanos fundamentais do homem, na dignidade e no valor do ser humano, [e] na igualdade de direito dos homens e das mulheres". ${ }^{38}$ Ela diz ademais que as Nações Unidas têm como propósito primeiro a realização da "cooperação internacional [...] para promover e estimular o respeito aos direitos humanos e às liberdades fundamentais para todos, sem distinção de raça, sexo, língua ou religião". ${ }^{39}$ A Carta acrescenta, no seu artigo 55, que as Nações Unidas têm que promover "o respeito universal e efetivo dos direitos humanos e das liberdades fundamentais para todos, sem distinção de raça, sexo, língua ou religião". ${ }^{40} \mathrm{O}$ artigo 56 declara que os estados-membros da

36 SOCIEDADE DAS NAÇÕES. Corte Permanente de Justiça. Minority Schools in Albania, Advisory Opinion of 6 April 1935, P.C.I.J. Series A/B. Judgments, Orders and Advisory Opinios, No. 64, 1935.

37 SOCIEDADE DAS NAÇÕES. Corte Permanente de Justiça. Minority Schools in Albania, Advisory Opinion of 6 April 1935, P.C.I.J. Series A/B. Judgments, Orders and Advisory Opinios, No. 64, 1935. p. 19 (tradução do autor).

38 NAÇõES UNIDAS. Assembleia Geral das Nações Unidas. Carta das Nações Unidas. 26 jun. 1945. Disponível em: https://www.oas.org/dil/port/1945\%20Carta\%20das\%20Na\%C3\%A7\%C3\%B5es\%20Unidas. pdf. Acesso em: 29 maio 2020. Preâmbulo.

39 NAÇõES UNIDAS. Assembleia Geral das Nações Unidas. Carta das Nações Unidas. 26 jun. 1945. Disponível em: https://www.oas.org/dil/port/1945\%20Carta\%20das\%20Na\%C3\%A7\%C3\%B5es\%20Unidas. pdf. Acesso em: 29 maio 2020. Art. 1, para. 3.

40 NAÇÕES UNIDAS. Assembleia Geral das Nações Unidas. Carta das Nações Unidas. 26 jun. 1945. Disponivel em: https://www.oas.org/dil/port/1945\%20Carta\%20das\%20Na\%C3\%A7\%C3\%B5es\%20Unidas. pdf. Acesso em: 29 maio 2020. Art. 55. 
Organização "se comprometem a agir em cooperação" com a Organização "em conjunto ou separadamente" para realizar este fim. ${ }^{41}$

A Declaração Universal de Direitos Humanos (“DUDH”), adotada três anos depois, promove "o reconhecimento da dignidade inerente a todos os membros da família humana e dos seus direitos iguais e inalienáveis". ${ }^{42}$ Ademais, ela afirma, no seu primeiro artigo, que: "Todos os seres humanos nascem livres e iguais em dignidade e direitos. Eles são dotados de razão e consciência e devem se comportar em relações com os outros num espírito de fraternidade" ${ }^{43} \mathrm{~A}$ Declaração proíbe a discriminação perante a lei. Particularmente, ela afirma que "Todos são iguais perante a lei e, sem distinção, têm direito a igual proteção da lei. Todos têm direito a proteção igual contra qualquer discriminação que viole a presente Declaração e contra qualquer incitamento a tal discriminação". ${ }^{44}$ Contudo, a Declaração não faz referência a medidas especiais para promover os direitos de populações vulneráveis.

De fato, cabe notar que, apesar das preocupações dos redatores da Carta e da DUDH com o tratamento cruel e injusto de membros de grupamentos minoritários, estes documentos colocam a ênfase sobre a igualdade de todos, e dão pouca atenção à situação particular de populações vulneráveis. A decisão foi tomada para enfatizar os direitos de cada pessoa, mas não de grupamentos ou populações específicas - provavelmente em parte por causa da preocupação de governos com não dar esperança a movimentos pela independência de grupamentos minoritários morando dentro das suas fronteiras e com o encorajamento da assimilação.

Ao respeito, esforços para incluir uma referência aos direitos de comunidades minoritárias na Declaração foram rejeitados pelos estados do Oeste, incluindo os Estados Unidos. Durante os debates, Eleanor Roosevelt declarou que foi "impossível adotar uma atitude neutral sobre a inserção na Declaração de um direito que não foi de significativa universal", e que "a melhor solução ao problema de minoridades foi de encorajar o respeito dos direitos humanos". ${ }^{45} 0$ Professor

41 NAÇÕES UNIDAS. Assembleia Geral das Nações Unidas. Carta das Nações Unidas. 26 jun. 1945. Disponível em: https://www.oas.org/dil/port/1945\%20Carta\%20das\%20Na\%C3\%A7\%C3\%B5es\%20 Unidas.pdf. Acesso em: 29 maio 2020. Art. 56.

42 NAÇÕES UNIDAS. Assembleia Geral das Nações Unidas. Declaração Universal dos Direitos Humanos (“DUDH”). G.A. Res. 217A (III) (1948). Disponivel em: https://www.ohchr.org/EN/UDHR/Documents/ UDHR_Translations/por.pdf. Acesso em: 29 maio 2020. Preâmbulo.

43 NAÇÕES UNIDAS. Assembleia Geral das Nações Unidas. Declaração Universal dos Direitos Humanos (“DUDH”). G.A. Res. 217A (III) (1948). Disponível em: https://www.ohchr.org/EN/UDHR/Documents/ UDHR_Translations/por.pdf. Acesso em: 29 maio 2020. Art. 1.

44 NAÇÕES UNIDAS. Assembleia Geral das Nações Unidas. Declaração Universal dos Direitos Humanos (“DUDH”). G.A. Res. 217A (III) (1948). Disponivel em: https://www.ohchr.org/EN/UDHR/Documents/ UDHR_Translations/por.pdf. Acesso em: 29 maio 2020. Art. 7.

45 Citado em THORNBERRY, Patrick. International Law and the Rights of Minorities. Oxford: Clarendon Press, 1991. p. 136 (tradução do autor). 
Patrick Thornberry conclui sobre o assunto: "Não e surpreendente que, no ver de um maioria de estados, os direitos humanos individualistas sem concessão especial alguma a grupos particulares na sociedade parecia um programa sensato, moderno, e democrático, completamente digno de apoio". ${ }^{46}$

Apesar desta lacuna, as Nações Unidas fizeram vários esforços para lidar com problemas particulares enfrentando grupos minoritários. Um tratado de uma importância marcante foi a Convenção contra o genocídio, adotada pela Assembleia Geral das Nações Unidas em 1948. A convenção obrigou os estados aderentes a proibir o genocídio e tomar medidas para proceder contra pessoas que o cometem. A definição do genocídio incorporou a noção de um grupamento vulnerável, particularmente "um grupo nacional, étnica, racial ou religioso". ${ }^{47}$ Em geral a convenção pode ser vista como uma medida mínima para assegurar os direitos à vida de membros destes grupos minoritários e à existência dos grupos em si.

O primeiro tratado a autorizar explicitamente medidas especiais para proteger populações vulneráveis foi a Convenção sobre a Eliminação de Todas Formas de Discriminação Racial, aprovada pela Assembleia Geral em 1965. O tratado declarou:

Não serão consideradas discriminação racial as medidas especiais tomadas com o único objetivo de assegurar o progresso adequado de certos grupos raciais ou étnicos ou de indivíduos que necessitem da proteção que possa ser necessária para proporcionar a tais grupos ou indivíduos igual gozo ou exercício de direitos humanos e liberdades fundamentais, contanto que tais medidas não conduzam, em consequência, à manutenção de direitos separados para diferentes grupos raciais e não prossigam após terem sido alcançados os seus objetivos. $^{48}$

46 THORNBERRY, Patrick. International Law and the Rights of Minorities. Oxford: Clarendon Press, 1991. p. 137 (tradução do autor). Sobre a falta de incluir os direitos de minorias na Declaração geralmente, veja p. 133-37.

47 NAÇÕES UNIDAS. Convenção para a Prevenção e a Repressão do Crime de Genocídio. 9 dez. 1948. Disponivel em: https://www.oas.org/dil/port/1948\%20Conven\%C3\%A7\%C3\%A3o\%20sobre\%20a\%20 Preven\%C3\%A7\%C3\%A30\%20e\%20Puni\%C3\%A7\%C3\%A3o\%20do\%20Crime\%20de\%20Genoc\%C3\%Addio. pdf. Acesso em: 29 maio 2020. Art. 2.

48 NAÇÕES UNIDAS. Assembleia Geral das Nações Unidas. Convenção sobre a Eliminação de Todas Formas de Discriminação Racial. 21 dez. 1965. Disponível em: https://www2.camara.leg.br/atividade-legislativa/ comissoes/comissoes-permanentes/cdhm/comite-brasileiro-de-direitos-humanos-e-politica-externa/ ConvintElimTodForDiscRac.html. Acesso em: 29 maio 2020. Art. 1, para. 4. 
Cabe notar alguns conceitos importantes latentes neste texto. Primeiro, a disposição permite medidas especiais apenas se o motivo de tais medidas seja legítimo. Segundo, o objetivo deve ser "proporcionar a tais grupos ou indivíduos" "igual gozo ou exercício de direitos humanos e liberdades fundamentais", o que significa a realização de direitos humanos de fato e não somente perante a lei. Terceiro, estas medidas não podem ter o efeito de manter "direitos separados para diferentes grupos raciais" e não podem ser mantidas "após terem sido alcançados os seus objetivos". Isso quer dizer que as medidas devem ser necessárias e temporárias, e não podem criar diferenças permanentes entre os direitos de grupamentos raciais diferentes.

Ademais, o artigo 2(2) da Convenção diz o seguinte:

Os Estados Membros tomarão, se as circunstâncias o exigirem, nos campos social, econômico, cultural e outros, medidas especiais e concretas para assegurar, como convier, o desenvolvimento ou a proteção de certos grupos raciais ou de indivíduos pertencentes a esses grupos, com o objetivo de garantir-lhes, em condições de igualdade, o pleno exercício dos direitos humanos e das liberdades fundamentais. Essas medidas não deverão, em caso algum, ter a finalidade de manter direitos desiguais ou distintos para os diversos grupos raciais, depois de alcançados os objetivos, em razão dos quais foram tomadas. ${ }^{49}$

É importante sublinhar novamente alguns pontos quanto a esta disposição. Ela coloca sobre os estados aderentes ao tratado a obrigação de tomar medidas especiais - não somente as permitindo - para assegurar o desenvolvimento ou a proteção de membros de certos grupos raciais. Uma vez mais, estas medidas não podem manifestar um propósito de manter direitos desiguais, e não podem ser mantidas depois que seus objetivos forem alcançados.

Em 1966, a Assembleia Geral adotou o texto de dois tratados criando obrigações judiciais baseadas nos direitos proclamados na DUDH - um tratado sobre os direitos civis e políticos (o Pacto Internacional sobre Direitos Civis e Políticos ("PIDCP")) e um outro sobre os direitos econômicos, sociais e culturais (o Pacto internacional sobre Direitos Econômicos, Sociais e Culturais ("PIDESC"))..$^{50}$

49 NAÇÕES UNIDAS. Assembleia Geral das Nações Unidas. Convenção sobre a Eliminação de Todas Formas de Discriminação Racial. 21 dez. 1965. Disponível em: https://www2.camara.leg.br/atividade-legislativa/ comissoes/comissoes-permanentes/cdhm/comite-brasileiro-de-direitos-humanos-e-politica-externa/ ConvIntElimTodForDiscRac.html. Acesso em: 29 maio 2020. Art. 2, para. 2.

50 Veja NAÇÕES UNIDAS. Assembleia Geral das Nações Unidas. Pacto Internacional sobre Direitos Civis e Políticos (PIDCP). 1966. Disponível em: http://www.planalto.gov.br/ccivil_03/decreto/1990-1994/ 
Em geral, ambos os tratados proclamam direitos gozados por todo o mundo sobre uma base de igualdade. Neste sentido, por exemplo, o PIDCP afirma no seu Artigo 26:

Todas as pessoas são iguais perante a lei e têm direito, sem discriminação alguma, a igual proteção da Lei. A este respeito, a lei deverá proibir qualquer forma de discriminação e garantir a todas as pessoas proteção igual e eficaz contra qualquer discriminação por motivo de raça, cor, sexo, língua, religião, opinião política ou de outra natureza, origem nacional ou social, situação econômica, nascimento ou qualquer outra situação. ${ }^{51}$

Durante a redação desta disposição e outros, o representante da Índia tentou inserir uma declaração de que medidas especiais seriam permitidas. Ele não conseguiu, mas os outros representantes concordaram em incluir nos relatórios sobre os debates uma tal declaração. ${ }^{52}$

O PIDCP não menciona medidas especiais para proteger populações vulneráveis. No entanto, Artigo 27 trata de minorias, e afirma:

Nos Estados em que haja minorias étnicas, religiosas ou linguísticas, as pessoas pertencentes a essas minorias não poderão ser privadas do direito de ter, conjuntamente com outros membros de seu grupo, sua própria vida cultural, de professar e praticar sua própria religião e usar sua própria língua. ${ }^{53}$

Esta disposição visa a proteger os direitos de membros de comunidades minoritárias, mas não contempla medidas especiais especificamente. Porém, pode ser que tais medidas possam ser necessárias para assegurar os direitos garantidos.

O PIDESC trata de medidas especiais apenas no contexto de crianças, afirmando no seu Artigo 10 que "Devem-se adotar medidas especiais de proteção e de assistência em prol de todas as crianças e adolescentes, sem distinção alguma por motivo de filiação ou qualquer outra condição". ${ }^{54}$ No entanto, é

D0592.htm. Acesso em: 29 maio 2020; NAÇÕES UNIDAS. Assembleia Geral das Nações Unidas. Pacto Internacional sobre Direitos Econômicos, Sociais e Culturais (PIDESC). 1966. Disponível em: http://www. planalto.gov.br/ccivil_03/decreto/1990-1994/D0591.htm. Acesso em: 29 maio 2020.

51 PIDCP, art. 26.

52 Veja Relatório do Repórter Especial, para. 47-48.

53 PIDCP, art. 27.

54 PIDESC, art. 10, para. 3. 
interessante notar, como apontado pelo repórter especial das NU sobre ações afirmativas, que também durante a elaboração do PIDESC o delegado da Índia introduziu a ideia de medidas especiais. Apesar de uma decisão de não incluir uma referência explícita a tais medidas, os representantes decidiram incluir uma declaração interpretativa nos relatórios da elaboração, clarificando que tais medidas são permitidas. ${ }^{55} \mathrm{E}$ este tratado clarifica a importância da igualdade de oportunidade quanto à promoção em empregos e à educação universitária. ${ }^{56}$ o Comitê estabelecido sob o tratado também tem adotado comentários defendendo o uso de medidas especiais temporárias relativas à educação. ${ }^{57}$

Treze anos depois da adoção do PIDCP e do PIDESC, a Assembleia deu sua aprovação a um tratado sobre os direitos das mulheres, a Convenção sobre a Eliminação de Todas as Formas de Discriminação contra a Mulher, adotada em 1979. ${ }^{58} \mathrm{O}$ artigo 4 da CEDAW afirma:

1. A adoção pelos Estados-partes de medidas especiais de caráter temporário destinadas a acelerar a igualdade de fato entre o homem e a mulher não se considerará discriminação na forma definida nesta Convenção, mas de nenhuma maneira implicará, como consequência, a manutenção de normas desiguais ou separadas; essas medidas cessarão quando os objetivos de igualdade de oportunidade e tratamento houverem sido alcançados.

2. A adoção pelos Estados-partes de medidas especiais, inclusive as contidas na presente Convenção, destinadas a proteger a maternidade, não se considerará discriminatória. ${ }^{59}$

Estas disposições ecoam aquelas na CERD. Uma vez mais, elas permitem a adoção de medidas especiais se elas têm o propósito de "acelerar" "igualdade de fato" e de estabelecer "igualdade de oportunidade e tratamento" e se elas são temporárias e não criam normas desiguais ou separadas permanentemente.

55 Relatório do Repórter Especial, para. 41.

56 Veja PIDESC, art. 7(c) (afirmando o direito à “igual oportunidade para todos de serem promovidos, em seu Trabalho, à categoria superior que Ihes corresponda, sem outras considerações que as de tempo de trabalho e capacidade"); art. 13, para. 2(c) (afirmando em parte que "a educação de nível superior deverá igualmente torna-se acessivel a todos, com base na capacidade de cada um").

57 Veja NAÇÕES UNIDAS. Comitê sobre os Direitos Econômicos, Sociais e Culturais. Comentário Geral No. 13. "The right to education (article 13 of the Covenant)". U.N. Doc. E/C.12/1999/10 (1999), para. 32-33. Veja também Relatório do Repórter Especial, para. 46.

58 NAÇÕES UNIDAS. Assembleia Geral das Nações Unidas. Convenção sobre a Eliminação de Todas as Formas de Discriminação contra a Mulher (CEDAW). 1979. Disponível em: http://www.pge.sp.gov.br/ centrodeestudos/bibliotecavirtual/instrumentos/discrimulher.htm. Acesso em: 29 maio 2020.

59 CEDAW, art. 4. 
Muitos outros documentos internacionais fazem referência à permissibilidade de várias medidas para promover os direitos de grupamentos vulneráveis. Por exemplo, dez anos depois da adoção de CEDAW, em 1989, a Assembleia Geral adotou a Convenção sobre os Direitos da Criança. ${ }^{60}$ Esta convenção permite uma variedade de medidas especiais para proteger crianças.

Em 1992, a Assembleia Geral das Nações Unidas adotou uma Declaração sobre os Direitos das Pessoas Pertencentes a Minorias Nacionais ou Étnicas, Religiosas e Linguísticas. De acordo com o artigo 4, por exemplo, "Os Estados adotarão as medidas necessárias a fim de garantir que as pessoas pertencentes a minorias possam exercer plena e eficazmente todos os seus direitos humanos $\mathrm{e}$ liberdades fundamentais sem discriminação alguma e em plena igualdade perante a Lei". ${ }^{61}$ Ademais, "Os estados deverão examinar as medidas apropriadas a fim de permitir que pessoas pertencentes a minorias possam participar plenamente do progresso e do desenvolvimento econômico de seu país". ${ }^{62}$

A Declaração também faz referência à legalidade e ética de medidas para promover os direitos de minorias, afirmando: "As medidas adotadas pelos Estados a fim de garantir o gozo dos direitos enunciados na presente Declaração não deverão ser consideradas prima facie contrárias ao princípio de igualdade contido na Declaração Universal de Direitos Humanos". 63

A Declaração dos Direitos dos Povos Indígenas, adotada pela Assembleia Geral das Nações Unidas em 2007, declara:

60 Veja NAÇõES UNIDAS. Convenção sobre os Direitos da Criança. 1989. Disponível em: http://www. planalto.gov.br/ccivil_03/decreto/1990-1994/D99710.htm. Acesso em: 29 maio 2020.

61 NAÇÕES UNIDAS. Assembleia Geral das Nações Unidas. Declaração sobre os Direitos das Pessoas Pertencentes a Minorias Nacionais ou Étnicas, Religiosas e Linguísticas. Aprovada pela resolução 47/135 da Assembleia Geral da ONU de 18 de dezembro de 1992. Disponível em: http://www. direitoshumanos.usp.br/index.php/Preven\%C3\%A7\%C3\%A3o-contra-a-Discrimina\%C3\%A7\%C3\%A3o-eProte\%C3\%A7\%C3\%A3o-das-Minorias/declaracao-sobre-os-direitos-das-pessoas-pertencentes-a-minoriasnacionais-ou-etnicas-religiosas-e-linguisticas.html. Acesso em: 29 maio 2020. Art. 4, para. 1.

62 NAÇÕES UNIDAS. Assembleia Geral das Nações Unidas. Declaração sobre os Direitos das Pessoas Pertencentes a Minorias Nacionais ou Étnicas, Religiosas e Linguísticas. Aprovada pela resolução 47/135 da Assembleia Geral da ONU de 18 de dezembro de 1992. Disponivel em: http://www. direitoshumanos.usp.br/index.php/Preven\%C3\%A7\%C3\%A3o-contra-a-Discrimina\%C3\%A7\%C3\%A3o-eProte\%C3\%A7\%C3\%A3o-das-Minorias/declaracao-sobre-os-direitos-das-pessoas-pertencentes-a-minoriasnacionais-ou-etnicas-religiosas-e-linguisticas.html. Acesso em: 29 maio 2020. Art. 4, para. 5.

63 NAÇÕES UNIDAS. Assembleia Geral das Nações Unidas. Declaração sobre os Direitos das Pessoas Pertencentes a Minorias Nacionais ou Étnicas, Religiosas e Linguísticas. Aprovada pela resolução 47/135 da Assembleia Geral da ONU de 18 de dezembro de 1992. Disponível em: http://www. direitoshumanos.usp.br/index.php/Preven\%C3\%A7\%C3\%A3o-contra-a-Discrimina\%C3\%A7\%C3\%A3o-eProte\%C3\%A7\%C3\%A3o-das-Minorias/declaracao-sobre-os-direitos-das-pessoas-pertencentes-a-minoriasnacionais-ou-etnicas-religiosas-e-linguisticas.html. Acesso em: 29 maio 2020. Art. 8, para. 3. 
os indígenas têm direito, como povos ou como pessoas, ao desfrute pleno de todos os direitos humanos e liberdades fundamentais reconhecidos pela Carta das Nações Unidas, pela Declaração Universal de Direitos Humanos e o direito internacional relativo aos direitos humanos. ${ }^{64}$

Ela diz também que "Os povos e indivíduos indígenas são livres e iguais a todos outros povos e indivíduos e têm o direito de ser livres de qualquer tipo de discriminação, no exercício dos seus direitos, particularmente aquela baseada sobre a sua origem indígena ou identidade". ${ }^{65}$

Algumas disposições da Declaração contemplam medidas especiais para promover os direitos de pessoas indígenas. Por exemplo, o Artigo 21 afirma:

1. Os povos indígenas têm o direito, sem discriminação, à melhoria das suas condições econômicas e sociais, incluindo, inter alia, nas áreas de educação, emprego, formação e reformação vocacionais, alojamento, saneamento, saúde e segurança social.

2. Os Estados tomarão medidas efetivas e, quando apropriadas, medidas especiais para assegurar a melhoria contínua das suas condições econômicas e sociais. Atenção especial será prestada aos direitos e necessidades especiais de idosos, mulheres, jovens, crianças, e pessoas com deficiência indígenas. ${ }^{66}$

Ademais, o Artigo 38 afirma geralmente que “os Estados, em consulta e cooperação com povos indígenas, tomarão as medidas apropriadas, incluindo medidas legislativas, para alcançar os fins desta Declaração" ${ }^{67}$

NAÇÕES UNIDAS. Assembleia Geral das Nações Unidas. Declaração das Nações Unidas sobre os Direitos dos Povos Indígenas. 13 set. 2007. Disponível em: https://pib.socioambiental.org/files/file/ PIB_institucional/DECLARACAO_DAS_NACOES_UNIDAS_SOBRE_OS_DIREITOS_DOS_POVOS_INDiGENAS. pdf. Acesso em: 29 maio 2020. Art. 1.

65 NAÇÕES UNIDAS. Assembleia Geral das Nações Unidas. Declaração das Nações Unidas sobre os Direitos dos Povos Indígenas. 13 set. 2007. Disponível em: https://pib.socioambiental.org/files/file/ PIB_institucional/DECLARACAO_DAS_NACOES_UNIDAS_SOBRE_OS_DIREITOS_DOS_POVOS_INDiGENAS. pdf. Acesso em: 29 maio 2020. Art. 2.

66 NAÇÕES UNIDAS. Assembleia Geral das Nações Unidas. Declaração das Nações Unidas sobre os Direitos dos Povos Indígenas. 13 set. 2007. Disponível em: https://pib.socioambiental.org/files/file/ PIB_institucional/DECLARACAO_DAS_NACOES_UNIDAS_SOBRE_OS_DIREITOS_DOS_POVOS_INDiGENAS. pdf. Acesso em: 29 maio 2020. Art. 21.

67 NAÇÕES UNIDAS. Assembleia Geral das Nações Unidas. Declaração das Nações Unidas sobre os Direitos dos Povos Indígenas. 13 set. 2007. Disponível em: https://pib.socioambiental.org/files/file/ PIB_institucional/DECLARACAO_DAS_NACOES_UNIDAS_SOBRE_OS_DIREITOS_DOS_POVOS_INDiGENAS. pdf. Acesso em: 29 maio 2020. Art. 38. 
Em 2007, as Nações Unidas também votaram em prol da Convenção sobre os Direitos de Pessoas com Deficiência. Esta convenção prescreve muitas medidas para ajudar estas pessoas a gozar efetivamente os seus direitos. Ela afirma especificamente que "Nos termos da presente Convenção, as medidas específicas que forem necessárias para acelerar ou alcançar a efetiva igualdade das pessoas com deficiência não serão consideradas discriminatórias". 68

Alguns documentos de organizações regionais também reconhecem a legalidade de medidas especiais. Não é possível aqui passar em revista todos estes documentos, mas cabe observar que a Convenção Europeia dos Direitos do Homem declara, no seu preâmbulo, que "o princípio da não-discriminação não obsta a que os Estados partes tomem medidas para promover uma igualdade plena e efetiva, desde que tais medidas sejam objetiva e razoavelmente justificadas". ${ }^{69}$ Ademais, a Carta dos Direitos Fundamentais da União Europeia, adotada em 2000, diz no seu Artigo 23 quanto à igualdade entre mulheres e homens que "o princípio da igualdade não obsta a que se mantenham ou adoptem medidas que prevejam regalias específicas a favor do sexo sub-representado". ${ }^{70}$

\section{A abordagem geral destas fontes de direito internacional à legalidade e à ética de medidas especiais para proteger populações vulneráveis}

Graça à revista acima de muitas fontes de direito internacional sobre medidas especiais, nós podemos identificar alguns temas comuns neste campo de direito. Primeiro, a igualdade perante a lei é crucial para todos, especialmente para populações vulneráveis, mas ela constitui um mínimo. 0 direito internacional reconhece a legalidade e a ética de medidas visando à realização de igualdade de fato, incluindo igualdade de oportunidade e de resultados, para pessoas desfavorecidas. Ao mesmo sentido, membros de grupos minoritários devem gozar do direito de praticar sua própria cultura com uma panóplia de direitos associados, como o direito de falar a sua própria língua e a exercer sua própria religião, entre outros.

68 NAÇÕES UNIDAS. Convenção sobre os Direitos de Pessoas com Deficiência. Disponível em: http://www. planalto.gov.br/ccivil_03/_Ato2007-2010/2009/Decreto/D6949.htm. Acesso em: 29 maio 2020. Art. 5, para. 4.

69 EUROPA. Conselho da Europa. Convenção para a Proteção dos Direitos do Homem e das Liberdades Fundamentais. Roma, 4.11.1950. Disponível em: https://www.echr.coe.int/Documents/Convention_ POR.pdf. Acesso em: 29 maio 2020. Preâmbulo.

70 UNIÃO EUROPEIA. Carta dos Direitos Fundamentais da União Europeia (2000). Jornal Oficial das Comunidades Europeias, 2000/C 364/01, 18 dez. 2000. Disponível em: http://europarl.europa.eu/ charter/pdf/text_pt.pdf. Acesso em: 29 maio 2020. Art. 23. 
À luz destas fontes, não seria apropriado chamar de medidas especiais uma forma de "discriminação positiva", porque elas não visam a qualquer tipo de discriminação, mas sim a eliminação de discriminação de fato. No entanto, os tratados sobre o assunto impõem limites sobre tais medidas. Particularmente, elas devem ser temporárias e não permanentes. Elas podem ser justificadas apenas até que os seus objetivos de igualdade de fato sejam alcançados, e não além deste tempo. E o propósito delas não pode ser a manutenção de um sistema de direitos diferentes para grupos diferentes.

Ademais, alguns dos tratados sobre os direitos humanos implicam não apenas que os Estados aderentes possam tomar tais medidas, mas sim que eles têm que adotar medidas eficazes para alcançar uma igualdade efetiva de fato entre populações vulneráveis e outros membros da sociedade.

Estas interpretações são suportadas por comentários e opiniões autorizativas exprimidas por comitês de especialistas estabelecidos por alguns tratados e por especialistas gerais no direito internacional. Por exemplo, o Comitê de CEDAW em 2004 explicou as exigências do artigo 4 sobre medidas especiais temporárias. Ele enfatizou que a Convenção visou a alcançar a igualdade de jure e de facto das mulheres com os homens no gozo dos seus direitos e liberdades fundamentais. ${ }^{71}$ Ele notou que a discriminação pode ser indireta, quando "leis, políticas, e programas são baseados em critérios aparentemente gênero-neutral que no seu efeito verdadeiro têm um impacto prejudicial sobre mulheres".$^{72} \mathrm{Na}$ opinião do Comitê, tais leis, políticas e programas "involuntariamente podem perpetuar as consequências de discriminação passada”. ${ }^{73}$

o Comitê elaborou:

Na visão do Comitê, uma abordagem puramente jurídico formal ou programática não é suficiente para alcançar a igualdade de fato de mulheres com homens, que o Comitê interpreta como igualdade substantiva. Ademais, a Convenção exige que mulheres sejam dotadas de

71 NAÇÕES UNIDAS. Committee on the Elimination of Discrimination Against Women. General Recommendation 25: Article 4, paragraph 1, of the Convention (temporary special measures). 30th session, 2004. Disponivel em: https://tbinternet.ohchr.org/Treaties/CEDAW/Shared\%20Documents/1_Global/INT_CEDAW_ GEC_3733_E.pdf. Acesso em: 29 maio 2020. Para. 4 (tradução do autor).

72 NAÇÕ̃ES UNIDAS. Committee on the Elimination of Discrimination Against Women. General Recommendation 25: Article 4, paragraph 1, of the Convention (temporary special measures). 30th session, 2004. Disponivel em: https://tbinternet.ohchr.org/Treaties/CEDAW/Shared\%20Documents/1_Global/INT_CEDAW_ GEC_3733_E.pdf. Acesso em: 29 maio 2020. Para. 7, n. 1 (tradução do autor).

73 NAÇÕ̃ES UNIDAS. Committee on the Elimination of Discrimination Against Women. General Recommendation 25: Article 4, paragraph 1, of the Convention (temporary special measures). 30th session, 2004. Disponivel em: https://tbinternet.ohchr.org/Treaties/CEDAW/Shared\%20Documents/1_Global/INT_CEDAW_ GEC_3733_E.pdf. Acesso em: 29 maio 2020. Para. 7, n. 1 (tradução do autor). 
um começo igual e que elas sejam empoderadas por um ambiente possibilitando para alcançar igualdade de resultados. Não é suficiente garantir às mulheres um tratamento que seja idêntico a aquele de homens. Em vez disso, diferenças biológicas assim como diferenças construídas socialmente e culturalmente devem ser tomando em conta. Sob certas circunstâncias, o tratamento não-idêntico de mulheres e homens será exigido a fim de endereçar tais diferenças. A perseguição da meta de igualdade substantiva também exige uma estratégia efetiva visando ao superar a sob representação de mulheres a ao redistribuir recursos e poder entre homens e mulheres. ${ }^{74}$

O Comitê adicionou que "Igualdade de resultados é o corolário logico de igualdade de fato ou substantiva". ${ }^{75}$ Ao respeito do significado do artigo 4(1), o Comitê esclareceu:

O propósito do Artigo 4, parágrafo 1, é acelerar a melhoria da posição de mulheres para alcançar a sua igualdade de fato ou substantiva com homens, e efetuar as mudanças estruturais, sociais, e culturais necessárias para corrigir formas passadas e atuais e efeitos de discriminação contra mulheres, assim como as fornecer de compensação. Estas medidas são de uma natura temporária. ${ }^{76}$

O Comitê explicou que esta obrigação de melhorar a posição de mulheres existe independentemente de qualquer prova de discriminação no passado. ${ }^{77}$ Ele também enfatizou que estados aderentes ao tratado têm uma obrigação geral de adotar políticas para melhorar a situação de mulheres e de meninas que não são de uma natureza temporária. Em contrapartida, as medidas exigidas pelo

74 NAÇÕES UNIDAS. Committee on the Elimination of Discrimination Against Women. General Recommendation 25: Article 4, paragraph 1, of the Convention (temporary special measures). 30th session, 2004. Disponível em: https://tbinternet.ohchr.org/Treaties/CEDAW/Shared\%20Documents/1_Global/INT_CEDAW_ GEC_3733_E.pdf. Acesso em: 29 maio 2020. Para. 8 (tradução do autor).

75 NAÇÕ̃ES UNIDAS. Committee on the Elimination of Discrimination Against Women. General Recommendation 25: Article 4, paragraph 1, of the Convention (temporary special measures). 30th session, 2004. Disponivel em: https://tbinternet.ohchr.org/Treaties/CEDAW/Shared\%20Documents/1_Global/INT_CEDAW_ GEC_3733_E.pdf. Acesso em: 29 maio 2020. Para. 9 (tradução do autor).

76 NAÇÕES UNIDAS. Committee on the Elimination of Discrimination Against Women. General Recommendation 25: Article 4, paragraph 1, of the Convention (temporary special measures). 30th session, 2004. Disponivel em: https://tbinternet.ohchr.org/Treaties/CEDAW/Shared\%20Documents/1_Global/INT_CEDAW_ GEC_3733_E.pdf. Acesso em: 29 maio 2020. Para. 15 (tradução do autor).

77 Veja NAÇÕES UNIDAS. Committee on the Elimination of Discrimination Against Women. General Recommendation 25: Article 4, paragraph 1, of the Convention (temporary special measures). 30th session, 2004. Disponível em: https://tbinternet.ohchr.org/Treaties/CEDAW/Shared\%20Documents/1_ Global/INT_CEDAW_GEC_3733_E.pdf. Acesso em: 29 maio 2020. Para. 18. 
artigo 4(1) “devem não ser consideradas necessárias para sempre, apesar de o significado de 'temporária' pode, de fato, resultar na aplicação de tais medidas durante muito tempo". ${ }^{78} \mathrm{Na}$ visão do Comitê, as medidas são denominadas "especiais" porque elas são desenhadas a alcançar uma meta específica. ${ }^{79}$

o Comitê afirmou que o termo "medidas" abrange

uma larga variedade de instrumentos, politicas, e práticas legislativos, executivos, administrativos, e regulamentários, tais como programas de divulgação ou sustenta; a alocação ou realocação de recursos; o tratamento preferencial; o recrutamento, a contratação, e a promoção visadas de funcionários; metas numéricas relacionadas com prazos; e sistemas de cotas. $^{80}$

Cabe ressaltar que o Comitê declarou que o artigo 4(1) tem que ser interpretado em relação a outras disposições da convenção estipulando que os estados aderentes têm que "adotar todas medidas necessárias". Consequentemente, o Comitê considerou que os estados aderentes são obrigados a adotar e implementar medidas especiais temporárias em relação a estes artigos se "tais medidas podem ser provadas a ser necessárias e apropriadas a fim de acelerar a conquista" da meta de igualdade de fato ou substantiva. ${ }^{81}$

O Comitê fez muitas recomendações aos estados aderentes sobre como cumprir estas obrigações. Ele avisou estados que eles têm que explicar qualquer falha de adotar medidas especiais temporárias, e que eles não podem justificar uma falha por afirmar a sua fraqueza, ou por invocar forças políticas ou do mercado. ${ }^{82}$

78 Veja NAÇÕES UNIDAS. Committee on the Elimination of Discrimination Against Women. General Recommendation 25: Article 4, paragraph 1, of the Convention (temporary special measures). 30th session, 2004. Disponivel em: https://tbinternet.ohchr.org/Treaties/CEDAW/Shared\%20Documents/1_ Global/INT_CEDAW_GEC_3733_E.pdf. Acesso em: 29 maio 2020. Para. 20 (tradução do autor).

79 NAÇõES UNIDAS. Committee on the Elimination of Discrimination Against Women. General Recommendation 25: Article 4, paragraph 1, of the Convention (temporary special measures). 30th session, 2004. Disponivel em: https://tbinternet.ohchr.org/Treaties/CEDAW/Shared\%20Documents/1_Global/INT_CEDAW_ GEC_3733_E.pdf. Acesso em: 29 maio 2020. Para. 21.

80 NAÇÕ̃ES UNIDAS. Committee on the Elimination of Discrimination Against Women. General Recommendation 25: Article 4, paragraph 1, of the Convention (temporary special measures). 30th session, 2004. Disponivel em: https://tbinternet.ohchr.org/Treaties/CEDAW/Shared\%20Documents/1_Global/INT_CEDAW_ GEC_3733_E.pdf. Acesso em: 29 maio 2020. Para. 22 (tradução do autor).

81 NAÇÕ̃ES UNIDAS. Committee on the Elimination of Discrimination Against Women. General Recommendation 25: Article 4, paragraph 1, of the Convention (temporary special measures). 30th session, 2004. Disponivel em: https://tbinternet.ohchr.org/Treaties/CEDAW/Shared\%20Documents/1_Global/INT_CEDAW_ GEC_3733_E.pdf. Acesso em: 29 maio 2020. Para. 24 (tradução do autor).

82 Veja NAÇÕES UNIDAS. Committee on the Elimination of Discrimination Against Women. General Recommendation 25: Article 4, paragraph 1, of the Convention (temporary special measures). 30th session, 2004. Disponivel em: https://tbinternet.ohchr.org/Treaties/CEDAW/Shared\%20Documents/1_ Global/INT_CEDAW_GEC_3733_E.pdf. Acesso em: 29 maio 2020. Para. 29. 
Eles devem explicar as suas abordagens e as bases das medidas. ${ }^{83} \mathrm{O}$ Comitê afirmou que estados aderentes devem incluir, nas suas constituições ou legislação nacional, disposições permitindo a adoção de medidas especiais temporárias. ${ }^{84}$ Ele indicou que legislação relevante deve abranger atores governamentais bem como organizações ou empresas privadas. O Comitê também disse que tais medidas podem ser baseadas em ações administrativas, e que elas podem ser "negociadas entre parceiros sociais do setor de emprego público ou privado ou ser aplicadas em uma base voluntaria por empresas, organizações, instituições, e partidos políticos públicos ou privados". ${ }^{85}$ Estados devem fornecer informações sobre as instituições responsáveis por aspetos vários de tais medidas, e devem incluir mulheres no desenho, implementação, e avaliação delas. ${ }^{86} 0$ Comitê ressaltou que em outras recomendações gerais ele recomendara a aplicação de medidas especiais temporárias nos campos da educação, da economia, da política e do emprego. ${ }^{87}$

O Comitê reafirmou que tais medidas devem ser adotadas para acelerar "a modificação e a eliminação de práticas culturais e atitudes e comportamento estereotípicos que discriminam contra ou são desvantajosas para mulheres". ${ }^{88}$ Em geral, ele recomendou que a adoção de tais medidas seja considerada "sempre que questões de acelerar acesso à participação igual, por um lado, e acelerar a redistribuição de poder e recursos, por outro lado, são envolvidas bem como onde

83 NAÇÕES UNIDAS. Committee on the Elimination of Discrimination Against Women. General Recommendation 25: Article 4, paragraph 1, of the Convention (temporary special measures). 30th session, 2004. Disponivel em: https://tbinternet.ohchr.org/Treaties/CEDAW/Shared\%20Documents/1_Global/INT_ CEDAW_GEC_3733_E.pdf. Acesso em: 29 maio 2020. Para. 30.

84 Veja NAÇÕES UNIDAS. Committee on the Elimination of Discrimination Against Women. General Recommendation 25: Article 4, paragraph 1, of the Convention (temporary special measures). 30th session, 2004. Disponivel em: https://tbinternet.ohchr.org/Treaties/CEDAW/Shared\%20Documents/1_ Global/INT_CEDAW_GEC_3733_E.pdf. Acesso em: 29 maio 2020. Para. 30.

85 NAÇÕES UNIDAS. Committee on the Elimination of Discrimination Against Women. General Recommendation 25: Article 4, paragraph 1, of the Convention (temporary special measures). 30th session, 2004. Disponivel em: https://tbinternet.ohchr.org/Treaties/CEDAW/Shared\%20Documents/1_Global/INT_ CEDAW_GEC_3733_E.pdf. Acesso em: 29 maio 2020. Para. 32 (tradução do autor).

86 Veja NAÇÕES UNIDAS. Committee on the Elimination of Discrimination Against Women. General Recommendation 25: Article 4, paragraph 1, of the Convention (temporary special measures). 30th session, 2004. Disponivel em: https://tbinternet.ohchr.org/Treaties/CEDAW/Shared\%20Documents/1_ Global/INT_CEDAW_GEC_3733_E.pdf. Acesso em: 29 maio 2020. Para. 34.

87 Veja NAÇÕES UNIDAS. Committee on the Elimination of Discrimination Against Women. General Recommendation 25: Article 4, paragraph 1, of the Convention (temporary special measures). 30th session, 2004. Disponivel em: https://tbinternet.ohchr.org/Treaties/CEDAW/Shared\%20Documents/1_ Global/INT_CEDAW_GEC_3733_E.pdf. Acesso em: 29 maio 2020. Para. 37.

88 NAÇÕES UNIDAS. Committee on the Elimination of Discrimination Against Women. General Recommendation 25: Article 4, paragraph 1, of the Convention (temporary special measures). 30th session, 2004. Disponivel em: https://tbinternet.ohchr.org/Treaties/CEDAW/Shared\%20Documents/1_Global/INT_ CEDAW_GEC_3733_E.pdf. Acesso em: 29 maio 2020. Para. 38 (tradução do autor). 
pode ser mostrado que estas medidas serão necessárias e mais apropriadas sob as circunstâncias". 89

No mesmo sentido, o Comitê criado pela Convenção sobre a Discriminação Racial, "CERD”, tem feito recomendações sobre a interpretação das disposições desse tratado tratando de medidas especiais. ${ }^{90}$ Primeiro, ele ressaltou que o termo “discriminação” sob a Convenção “inclui discriminação intencional e discriminação em efeito". ${ }^{91}$ Ele disse:

a discriminação é constituída não simplesmente por uma "distinção, exclusão, ou restrição” injustificável, mas sim por uma preferência injustificável, fazendo com que é especialmente importante pelos Estados aderentes distinguir "medidas especiais" de preferencias injustificáveis. ${ }^{92}$

\section{O Comitê disse sobre o conceito de "não discriminação":}

O termo “não-discriminação" não significa a necessidade de tratamento uniforme quando existem diferenças significativas de situação entre uma pessoa ou um grupo e um outro, ou, em outras palavras, se existe uma justificativa objetiva e razoável pelo tratamento diferencial. Tratar de uma maneira igual pessoas ou grupos cujas situações são diferentes objetivamente constituirá discriminação em efeito, como também o tratamento desigual de pessoas cujas situações são objetivamente as mesmas. ${ }^{93}$

89 NAÇÕES UNIDAS. Committee on the Elimination of Discrimination Against Women. General Recommendation 25: Article 4, paragraph 1, of the Convention (temporary special measures). 30th session, 2004. Disponivel em: https://tbinternet.ohchr.org/Treaties/CEDAW/Shared\%20Documents/1_Global/INT_CEDAW_ GEC_3733_E.pdf. Acesso em: 29 maio 2020. Para. 39 (tradução do autor).

90 NAÇÕ̃ES UNIDAS. Committee on the Elimination of Racial Discrimination. General Recommendation No. 32. The Meaning and Scope of Special Measures in the International Convention on the Elimination of All forms of Racial Discrimination. U.N. Doc. CERD/C/GC/32 (2009). Disponível em: https://tbinternet. ohchr.org/_layouts/15/treatybodyexternal/Download.aspx?symbolno=CERD\%2fC\%2fGC\%2f32\&Lang=en. Acesso em: 29 maio 2020.

91 NAÇÕES UNIDAS. Committee on the Elimination of Racial Discrimination. General Recommendation No. 32. The Meaning and Scope of Special Measures in the International Convention on the Elimination of All forms of Racial Discrimination. U.N. Doc. CERD/C/GC/32 (2009). Disponível em: https://tbinternet. ohchr.org/_layouts/15/treatybodyexternal/Download.aspx?symbolno=CERD\%2fC\%2fGC\%2f32\&Lang=en. Acesso em: 29 maio 2020. Para. 7 (tradução do autor).

92 NAÇÕES UNIDAS. Committee on the Elimination of Racial Discrimination. General Recommendation No. 32. The Meaning and Scope of Special Measures in the International Convention on the Elimination of All forms of Racial Discrimination. U.N. Doc. CERD/C/GC/32 (2009). Disponível em: https://tbinternet. ohchr.org/_layouts/15/treatybodyexternal/Download.aspx?symbolno=CERD\%2fC\%2fGC\%2f32\&Lang=en. Acesso em: 29 maio 2020. Para. 7 (tradução do autor).

93 NAÇÕES UNIDAS. Committee on the Elimination of Racial Discrimination. General Recommendation No. 32. The Meaning and Scope of Special Measures in the International Convention on the Elimination of 
O Comitê definiu "medidas" largamente, e disse que estados aderentes devem incluir disposições sobre medidas especiais nos seus sistemas jurídicos. ${ }^{94}$ o Comitê também distinguiu medidas especiais temporárias de direitos humanos permanentes, tais como os direitos de minorias a gozar da sua cultura, do professar, de praticar a sua religião própria e de falar a sua língua. Ele igualmente distinguiu medidas temporárias dos direitos de povos indígenas, incluindo direitos a terrenos tradicionalmente ocupados por eles, e direitos de mulheres a um tratamento não idêntico aos homens, tais como a provisão de licença-maternidade, por conta de diferenças biológicas com os homens. ${ }^{95}$

O Comitê estabeleceu limites sobre medidas especiais, afirmando sobre elas:

devem ser apropriadas à situação a ser remediada, ser legitimas [e] necessárias em uma sociedade democrática, respeitar os princípios de justiça e proporcionalidade, e ser temporárias. As medidas devem ser desenhadas e implementadas na base de necessidade, ancoradas em uma avaliação realística da situação atual dos indivíduos e comunidades interessados. ${ }^{96}$

O Comitê clarificou que de acordo com o texto do Artigo 1(4) da Convenção, "medidas especiais não são uma exceção ao princípio de não-discriminação, mas sim uma parte integral a sua significativa e essenciais ao propósito da convenção de eliminar a discriminação racial e de avançar a dignidade humana e igualdade efetiva" ${ }^{97}$ O Comitê adicionou que a noção de "avanço adequado" no Artigo 1(4)

All forms of Racial Discrimination. U.N. Doc. CERD/C/GC/32 (2009). Disponível em: https://tbinternet. ohchr.org/_layouts/15/treatybodyexternal/Download.aspx?symbolno=CERD\%2fC\%2fGC\%2f32\&Lang=en. Acesso em: 29 maio 2020. Para. 8 (tradução do autor).

94 Veja NAÇÕES UNIDAS. Committee on the Elimination of Racial Discrimination. General Recommendation No. 32. The Meaning and Scope of Special Measures in the International Convention on the Elimination of All forms of Racial Discrimination. U.N. Doc. CERD/C/GC/32 (2009). Disponivel em: https://tbinternet. ohchr.org/_layouts/15/treatybodyexternal/Download.aspx?symbolno=CERD\%2fC\%2fGC\%2f32\&Lang=en. Acesso em: 29 maio 2020. Para. 13.

95 Veja NAÇÕES UNIDAS. Committee on the Elimination of Racial Discrimination. General Recommendation No. 32. The Meaning and Scope of Special Measures in the International Convention on the Elimination of All forms of Racial Discrimination. U.N. Doc. CERD/C/GC/32 (2009). Disponivel em: https://tbinternet. ohchr.org/_layouts/15/treatybodyexternal/Download.aspx?symbolno=CERD\%2fC\%2fGC\%2f32\&Lang=en. Acesso em: 29 maio 2020. Para. 5.

96 NAÇÕES UNIDAS. Committee on the Elimination of Racial Discrimination. General Recommendation No. 32. The Meaning and Scope of Special Measures in the International Convention on the Elimination of All forms of Racial Discrimination. U.N. Doc. CERD/C/GC/32 (2009). Disponivel em: https://tbinternet. ohchr.org/_layouts/15/treatybodyexternal/Download.aspx?symbolno=CERD\%2fC\%2fGC\%2f32\&Lang=en. Acesso em: 29 maio 2020. Para. 16 (tradução do autor).

97 NAÇÕES UNIDAS. Committee on the Elimination of Racial Discrimination. General Recommendation No. 32. The Meaning and Scope of Special Measures in the International Convention on the Elimination of All forms of Racial Discrimination. U.N. Doc. CERD/C/GC/32 (2009). Disponivel em: https://tbinternet. 
implica "programas dirigidas por metas e que têm o objetivo ao aliviar e remediar disparidades no gozo de direitos humanos e liberdades fundamentais afetando grupos e indivíduos particulares, protegendo os de discriminação". ${ }^{98}$ Parecido ao Comitê de CEDAW, o Comitê sublinhou que "não é necessário comprovar discriminação 'histórica' a fim de validar um programa de medidas especiais; a ênfase deve ser colocada em corrigindo disparidades atuais e em impedindo a ocorrência de novos desequilíbrios". ${ }^{99}$

Segundo o Comitê, o Artigo 1(4) indica que o uso do termo "proteção" implica que medidas podem ter uma função preventiva ao respeito de violações de direitos humanos bem como funções corretivas. ${ }^{100} \mathrm{O}$ Comitê também destacou alguns limites explícitos no texto, incluindo que medidas especiais não devem levar à manutenção de direitos separados por grupos raciais diferentes. 0 Comitê apontou que esta disposição é estreitamente escrita e chama atenção para um sistema tal como apartheid e práticas de segregação. Ele afirmou:

a noção de "direitos separados" inaceitáveis deve ser distinguida de direitos aceitos e reconhecidos pela comunidade internacional para assegurar a existência e a identidade de grupos tais como minoridades, povos indígenas e outras categorias de pessoas cujos direitos são aceitos e reconhecidos similarmente dentro da estrutura de direitos humanos universais. ${ }^{101}$

ohchr.org/_layouts/15/treatybodyexternal/Download.aspx?symbolno=CERD\%2fC\%2fGC\%2f32\&Lang=en. Acesso em: 29 maio 2020. Para. 20 (tradução do autor).

98 NAÇÕES UNIDAS. Committee on the Elimination of Racial Discrimination. General Recommendation No. 32. The Meaning and Scope of Special Measures in the International Convention on the Elimination of All forms of Racial Discrimination. U.N. Doc. CERD/C/GC/32 (2009). Disponivel em: https://tbinternet. ohchr.org/_layouts/15/treatybodyexternal/Download.aspx?symbolno=CERD\%2fC\%2fGC\%2f32\&Lang=en. Acesso em: 29 maio 2020. Para. 22 (tradução do autor).

99 NAÇõES UNIDAS. Committee on the Elimination of Racial Discrimination. General Recommendation No. 32. The Meaning and Scope of Special Measures in the International Convention on the Elimination of All forms of Racial Discrimination. U.N. Doc. CERD/C/GC/32 (2009). Disponivel em: https://tbinternet. ohchr.org/_layouts/15/treatybodyexternal/Download.aspx?symbolno=CERD\%2fC\%2fGC\%2f32\&Lang=en. Acesso em: 29 maio 2020. Para. 22 (tradução do autor).

100 Veja NAÇÕES UNIDAS. Committee on the Elimination of Racial Discrimination. General Recommendation No. 32. The Meaning and Scope of Special Measures in the International Convention on the Elimination of All forms of Racial Discrimination. U.N. Doc. CERD/C/GC/32 (2009). Disponivel em: https://tbinternet. ohchr.org/_layouts/15/treatybodyexternal/Download.aspx?symbolno=CERD\%2fC\%2fGC\%2f32\&Lang=en. Acesso em: 29 maio 2020. Para. 23.

101 NAÇÕES UNIDAS. Committee on the Elimination of Racial Discrimination. General Recommendation No. 32. The Meaning and Scope of Special Measures in the International Convention on the Elimination of All forms of Racial Discrimination. U.N. Doc. CERD/C/GC/32 (2009). Disponivel em: https://tbinternet. ohchr.org/_layouts/15/treatybodyexternal/Download.aspx?symbolno=CERD\%2fC\%2fGC\%2f32\&Lang=en. Acesso em: 29 maio 2020. Para. 26 (tradução do autor). 
O Comitê também explicou a exigência de que medidas especiais não sejam perpetuadas depois que os seus objetivos tenham sido alcançados. Ele concluiu que este limite é funcional; portanto:

o prazo de tempo permitido pela duração das medidas variará à luz dos seus objetivos, os meios utilizados para os alcançar, e os resultados da sua aplicação. Medidas especiais devem, portanto, ser cuidadosamente costuradas a cumprir as necessidades particulares dos grupos ou indivíduos interessados. ${ }^{102}$

O Comitê elaborou sobre as exigências do Artigo 2(2), exigindo que estados aderentes tomem medidas especiais e concretas para assegurar o desenvolvimento e proteção adequados de grupos raciais ou indivíduos pertencendo a eles. ${ }^{103}$ $\mathrm{Na}$ opinião do Comitê, este artigo leva em diante o conceito de medidas especiais no Artigo 1(4) e "indica a natura obrigatória da obrigação de tomar tais medidas". ${ }^{104}$ o Comitê sublinhou que os limites sobre medidas especiais no Artigo 2(2) são parecidos aos limites no Artigo 1(4). Ele afirmou que a exigência de limitar o prazo de tais medidas implica a necessidade de um sistema contínuo para monitorar a sua aplicação e resultados "usando, como apropriado, medidas quantitativas e qualitativas de avaliação". ${ }^{105}$ Ademais, o Comitê avisou:

Estados aderentes devem [...] determinar cuidadosamente se consequências negativas sobre direitos humanos aconteceriam para comunidades beneficiadas como resultado de uma retirada abrupta de

102 NAÇÕES UNIDAS. Committee on the Elimination of Racial Discrimination. General Recommendation No. 32. The Meaning and Scope of Special Measures in the International Convention on the Elimination of All forms of Racial Discrimination. U.N. Doc. CERD/C/GC/32 (2009). Disponivel em: https://tbinternet. ohchr.org/_layouts/15/treatybodyexternal/Download.aspx?symbolno=CERD\%2fC\%2fGC\%2f32\&Lang=en. Acesso em: 29 maio 2020. Para. 27 (tradução do autor).

${ }^{103}$ Veja NAÇÕES UNIDAS. Committee on the Elimination of Racial Discrimination. General Recommendation No. 32. The Meaning and Scope of Special Measures in the International Convention on the Elimination of All forms of Racial Discrimination. U.N. Doc. CERD/C/GC/32 (2009). Disponivel em: https://tbinternet. ohchr.org/_layouts/15/treatybodyexternal/Download.aspx?symbolno=CERD\%2fC\%2fGC\%2f32\&Lang=en. Acesso em: 29 maio 2020. Para. 28.

104 NAÇÕES UNIDAS. Committee on the Elimination of Racial Discrimination. General Recommendation No. 32. The Meaning and Scope of Special Measures in the International Convention on the Elimination of All forms of Racial Discrimination. U.N. Doc. CERD/C/GC/32 (2009). Disponivel em: https://tbinternet. ohchr.org/_layouts/15/treatybodyexternal/Download.aspx?symbolno=CERD\%2fC\%2fGC\%2f32\&Lang=en. Acesso em: 29 maio 2020. Para. 30 (tradução do autor).

105 NAÇÕES UNIDAS. Committee on the Elimination of Racial Discrimination. General Recommendation No. 32. The Meaning and Scope of Special Measures in the International Convention on the Elimination of All forms of Racial Discrimination. U.N. Doc. CERD/C/GC/32 (2009). Disponivel em: https://tbinternet. ohchr.org/_layouts/15/treatybodyexternal/Download.aspx?symbolno=CERD\%2fC\%2fGC\%2f32\&Lang=en. Acesso em: 29 maio 2020. Para. 35 (tradução do autor). 
medidas especiais, especialmente se elas têm sido estabelecidas por um período longo de tempo. ${ }^{106}$

O Comitê de Direitos Humanos estabelecido pelo PIDCP também tem exprimido uma visão favorável a medidas especiais para proteger populações vulneráveis e visando a assegurar a sua igualdade de fato. No seu comentário geral sobre o Artigo 26, ele afirmou:

O princípio de igualdade as vezes exige que os Estados aderentes tomem ação afirmativa para diminuir ou eliminar condições que causam ou ajudam a perpetuar discriminação proibida pelo Pacto. Por exemplo, em um Estado onde as condições gerais de uma certa parte da população evitam ou prejudicam o seu gozo de direitos humanos, o Estado deve tomar ação específica para corrigir estas condições. Tal ação pode envolver dotando por um tempo a parte da população interessada certo tratamento preferencial em assuntos específicos em comparação com o resto da população. No entanto, desde que tal ação é necessária para corrigir discriminação em fato, é um caso de diferenciação legitima sob o Pacto. ${ }^{107}$

O Comitê também clarificou que "o gozo de direitos e liberdades em um pé de igualdade não significa tratamento idêntico em cada instancia", e que "não cada diferenciação de tratamento constituirá discriminação, se os critérios para tal diferenciação são razoáveis e objetivos e se o alvo é de alcançar um proposito que é legitimo sob o Pacto". ${ }^{108}$ A Corte Europeia de Direitos Humanos tem adotado uma interpretação parecida com a da Convenção Europeia de Direitos Humanos. ${ }^{109}$ Portanto, o repórter especial das NU sobre ações afirmativas concluiu que o termo “discriminação" não faz referência a qualquer distinção, mas a "diferenças arbitrárias e ilegais de tratamento". ${ }^{110}$

106 NAÇÕES UNIDAS. Committee on the Elimination of Racial Discrimination. General Recommendation No. 32. The Meaning and Scope of Special Measures in the International Convention on the Elimination of All forms of Racial Discrimination. U.N. Doc. CERD/C/GC/32 (2009). Disponível em: https://tbinternet. ohchr.org/_layouts/15/treatybodyexternal/Download.aspx?symbolno=CERD\%2fC\%2fGC\%2f32\&Lang=en. Acesso em: 29 maio 2020. Para. 35 (tradução do autor).

107 NAÇÕES UNIDAS. Comitê dos Direitos Humanos. Comentário Geral No. 18. U.N. Doc. HRI/GEN/1/Ver.4 (2000). Disponível em: https://tbinternet.ohchr.org/_layouts/15/treatybodyexternal/Download.aspx?sym bolno=INT\%2fCCPR\%2fGEC\%2f6622\&Lang=en. Acesso em: 29 maio 2020. Para. 10 (tradução do autor).

108 NAÇÕES UNIDAS. Comitê dos Direitos Humanos. Comentário Geral No. 18. U.N. Doc. HRI/GEN/1/Ver.4 (2000). Disponível em: https://tbinternet.ohchr.org/_layouts/15/treatybodyexternal/Download.aspx?sym bolno=INT\%2fCCPR\%2fGEC\%2f6622\&Lang=en. Acesso em: 29 maio 2020. Para. 8, 13.

109 Veja Relatório do Repórter Especial, para. 86-90.

110 Veja Relatório do Repórter Especial, para. 91(a) (tradução do autor). 
Ademais, alguns especialistas têm concluído geralmente que "o conceito de ações afirmativas não é contrário à lei dos Pactos". ${ }^{111}$ Portanto, sobre estes pontos existe um grau de acordo internacional.

Muitos observadores também têm argumentado que os princípios de não discriminação e de igualdade formam parte do direito internacional consuetudinário. ${ }^{112}$ As fontes citadas geralmente sustentam esta conclusão. No entanto, o estatuto de uma permissão ou mesmo de uma obrigação de adotar medidas especiais é muito mais incerto, como vou discutir.

\section{Questões restantes}

Apesar dos temas comuns que eu acabei de identificar, restam muitas dúvidas sobre a legalidade e a ética de medidas especiais. Primeiro, as disposições dos tratados como CERD e CEDAW são apenas uma exceção limitada, até em tempo, ao princípio de igualdade perante a lei que devem ser interpretadas estreitamente? Ou por outro lado, podem estas disposições constituir um novo princípio importante que deve ser enfatizado em si? Existem também dúvidas importantes sobre a natureza obrigatória de implementar medidas especiais. Apesar de os Comitês de CERD e CEDAW afirmarem que estes tratados impõem uma tal obrigação, o repórter especial das NU sobre ações afirmativas disse que os dois pactos não o fazem, afirmando que "deve-se ser ressaltado que nenhum dos Pactos tem reconhecido explicitamente qualquer natura obrigatória de ação afirmativa". ${ }^{113}$

Ademais, como determinar se uma medida para uma população específica é justificada em primeiro lugar? É necessário que a população tenha sofrido discriminação historicamente, ou somente que atualmente os seus membros são desfavorecidos? Os comitês dos tratados relevantes concordam que discriminação atual é suficiente, mas outros podem duvidar que um grupo merece um tratamento preferido sem uma tal história. E que constitui discriminação suficiente contra esta população? Muitos grupos podem reclamar tratamento especial.

Ao outro extremo, mesmo se uma medida possa ser justificada incialmente, como deve se determinar se os seus objetivos são alcançados? Como deve ela ser

\footnotetext{
${ }^{111}$ Relatório do Repórter Especial, para. 53, referenciando as conclusões de Patrick Thornberry (tradução do autor).

112 Veja LEPARD, Brian D. Customary International Law: A New Theory with Practical Applications. New York: Cambridge University Press, 2010. p. 342. O Repórter Especial das Nações Unidas concorda com esta visão. Veja Relatório do Repórter Especial, p. 33 n. 60.

113 Relatório do Repórter Especial, para. 53 (tradução do autor).
} 
medida? É possível que medidas possam durar muito tempo até que elas quase se tornem permanentes? Neste caso, como evitar violar o requisito dos tratados que uma medida não possa criar paquetes de direitos diferentes permanentes para grupos distintos? Ao respeito, o repórter especial das Nações Unidas sobre ações afirmativas criticou a extensão indefinida de muitas medidas supostamente “temporárias". 114

Outras questões relevantes são: Como podem ser implementadas medidas para apoiar um grupo, como cotas, sem ferir membros de um outro grupo não designado um grupo-alvo, mas que também merece consideração especial? Para definição, uma cota reserva uma vaga para um membro de um grupo-alvo em negando a vaga a um membro de um outro grupo que de outra forma teria merecido a vaga. Neste sentido, o repórter especial das Nações Unidas sobre as ações afirmativas, Marc Bossuyt, concluiu que medidas como "mobilização afirmativa", nas quais membros de grupos-alvo são encorajados agressivamente a fazer aplicação para uma vaga, ou medidas de "justiça afirmativa", nas quais um exame exaustivo acontece para assegurar que membros de um grupo-alvo tenham sido tratados justamente quanto a um emprego, não são controvertidas. No entanto, o repórter especial concluiu que medidas tomando a forma de "preferências afirmativas", como cotas, podem ser problemáticas se as preferências não forem conferidas apenas se os candidatos-alvo forem tão qualificados quanto outros. Ele afirmou que "uma injustiça não pode ser reparada por uma outra injustiça". ${ }^{115}$ E ele disse que o princípio de igualdade e não discriminação se tornaria sem significado se medidas que privam manifestamente pessoas de direitos na base de critérios que não são relevantes ao direito envolvido fossem justificadas por chamando tais medidas "ações afirmativas". ${ }^{116}$ Ele adicionou: "Em nenhum caso pode alguém ser privado de um direito básico sob o pretexto que fazendo isso ajudaria grupos particularmente desfavorecidos superar melhor as consequências de discriminação anterior". ${ }^{117}$

Como abordado antes, o papel da diversidade ao justificar medidas especiais é o sujeito de muitas disputas, e os textos internacionais não resolvem explicitamente estes debates. Além disso, muitos observadores têm argumentado que medidas especiais mesmo ferem os membros do grupo-alvo, porque eles não podem ter a confiança que eles merecem, o benefício que eles receberam de acordo com as medidas, e as demais pessoas duvidarão que eles os merecem, produzindo autodúvida e uma falta de confiança.

\footnotetext{
114 Relatório do Repórter Especial, para. 106 (tradução do autor).

115 Relatório do Repórter Especial, para. 108 (tradução do autor).

116 Relatório do Repórter Especial.

117 Relatório do Repórter Especial, para. 112 (tradução do autor).
} 
Nós podemos ir além destes tipos de perguntas e buscar determinar se algumas das normas exprimidas em tratados particulares passaram para o campo do direito internacional consuetudinário. Isso significaria que todos os estados no mundo, não importa se eles tenham ratificado tratados específicos, tenham a obrigação de implementar medidas especiais sob condições apropriadas, como aquelas especificadas nos tratados e discutidas acima.

\section{Para uma nova teoria sobre a legalidade e a ética de medidas especiais para proteger os direitos de populações vulneráveis sob o direito internacional}

Pelas razões explicadas acima, nós precisamos de uma nova teoria sobre como interpretar estas disposições de tratados, declarações, a outras fontes relevantes de direito internacional. Aqui eu tento esboçar uma teoria baseada em princípios éticos fundamentais encontrados dentro do direito internacional contemporâneo e apoiados pelas escrituras santas de muitas religiões e filosofias mundiais. Eu já tenho elaborado alguns elementos de uma tal teoria nas minhas outras obras.

Para dar um panorama geral da minha teoria, tenho proposto que a interpretação de tratados e do direito consuetudinário tem que ser feita à luz de "princípios éticos fundamentais". 118 Eu defino estes princípios como princípios que têm sido reconhecidos por estados no direito internacional contemporâneo, incluindo a Carta das Nações Unidas e a Declaração Universal dos Direitos Humanos, e que logicamente se relacionam a um princípio preeminente de “unidade em diversidade". 119

Segundo este princípio, todos os seres humanos devem ser unificados, nos planos moral e social, como membros de uma única família, mas ao mesmo tempo podem ser orgulhosos quanto às suas culturas e identidades diversas. ${ }^{120}$ Nós podemos encontrar um reconhecimento deste princípio na DUDH, o primeiro artigo que declara que "Todos os seres humanos nascem livres e iguais em dignidade

118 Veja em geral LEPARD, Brian D. Rethinking Humanitarian Intervention: A Fresh Legal Approach Based on Fundamental Ethical Principles in International Law and World Religions. Pennsylvania: Penn State University Press, 2002. p. 99-118.

119 Veja LEPARD, Brian D. Rethinking Humanitarian Intervention: A Fresh Legal Approach Based on Fundamental Ethical Principles in International Law and World Religions. Pennsylvania: Penn State University Press, 2002. p. 39.

120 Veja LEPARD, Brian D. Rethinking Humanitarian Intervention: A Fresh Legal Approach Based on Fundamental Ethical Principles in International Law and World Religions. Pennsylvania: Penn State University Press, 2002. p. 33-34. 
e em direitos. Dotados de razão e de consciência, devem agir uns para com os outros em espírito de fraternidade". ${ }^{121}$ Ao mesmo tempo, esta Declaração sustenta a liberdade de ter crenças e opiniões diversas, ${ }^{122}$ e a Carta das Nações Unidas defende as perspectivas diferentes de estados e faz referência à organização como "um centro destinado a harmonizar a ação das nações para a consecução" de objetivos comuns. ${ }^{123}$ Outros documentos afirmam explicitamente o valor da diversidade. Por exemplo, a Declaração de Unesco sobre a Raça e os Preconceitos Raciais de 1978 diz que "todos os indivíduos e os grupos têm o direito de serem diferentes, a se considerar e serem considerados como tais". ${ }^{124}$

Um elemento importante da abordagem que tenho desenvolvido é mostrar que estes princípios éticos fundamentais no direito internacional encontram apoio em passagens aparecendo nas escrituras santas das maiores religiões e filosofias mundiais. Este fato Ihes dá mais força e legitimidade em servindo como uma fundação para uma nova abordagem à interpretação do direito internacional. ${ }^{125}$

Nós podemos identificar uma panóplia de princípios identificados no direito internacional contemporâneo e relacionados ao princípio supremo de unidade em diversidade. Estes incluem a dignidade humana e os direitos humanos; a responsabilidade de governos de proteger e promover o bem-estar das pessoas morando nos territórios sob o seu controle; a liberdade das pessoas de fazer escolhas morais; a resolução de conflitos e de questões difíceis por um processo de consulta com mente aberta; a promoção da noção da visão de uma comunidade global de estados e pessoas comprometidos a promover princípios éticos; e a obrigação de cumprir as promissões em tratados internacionais. ${ }^{126}$

Relacionado especificamente ao problema das ações afirmativas é um outro princípio ético fundamental: a ideia de que todas as pessoas humanas constituam uma família e que esta família inteira é ferida se um membro dela esteja doente ou vulnerável. Claramente este princípio flui do princípio da unidade em diversidade. Cabe ressaltar que ele vai além de prescrever a igualdade perante a lei dos membros desta família. Ele sugere também que todos os membros da

${ }^{21} \mathrm{DUDH}$, art. 1.

122 Veja DUDH, art. 18.

${ }^{123}$ Carta das Nações Unidas, art. 1, para. 4.

124 NAÇÕES UNIDAS. Declaração sobre a Raça e os Preconceitos Raciais. Conferência Geral da Organização das Nações Unidas para a Educação, a Ciência e a Cultura, reunida em Paris em sua 20 reunião, em 27 de novembro de 1978. Disponível em: http://dhnet.org.br/direitos/sip/onu/discrimina/dec78.htm. Acesso em: 29 maio 2020. Art. 1, para. 2.

125 Sobre este apoio, veja LEPARD, Brian D. Rethinking Humanitarian Intervention: A Fresh Legal Approach Based on Fundamental Ethical Principles in International Law and World Religions. Pennsylvania: Penn State University Press, 2002. p. 45-50.

126 Veja LEPARD, Brian D. Customary International Law. A New Theory with Practical Applications. New York: Cambridge University Press, 2010. p. 81-92. 
família humana têm que gozar uma igualdade que é verdadeira e efetiva, que nós temos chamado "igualdade de fato". No entanto, o princípio implica até mais: que a existência de desigualdade de qualquer tipo fere a família humana e, portanto, que esta família deve fazer esforços para ajudar populações vulneráveis e the prestar uma atenção e um cuidado especiais - não somente para as apoiar, mas sim elevar o bem-estar moral da população inteira. E este princípio implica também que a diversidade entre os membros desta família humana tem um valor muito importante em si. Nós poderíamos chamar este princípio de "interdependência familiar".

Este princípio latente, mas não explícito, nos documentos de direito internacionais encontra apoio em passagens selecionadas de escrituras reverenciadas religiosas e filosóficas. Por exemplo, ao respeito do conceito de uma família humana que deve ser unida, as escrituras hebraicas afirmam: "Não todos nós temos um único pai? Não um único Deus nos criou?". ${ }^{127}$ Jesus também asseverou que todas as pessoas são os filhos de Deus: "Chame ninguém o seu pai na terra, porque vocês têm um único Pai - aquele no céu" ${ }^{128}$ O Alcorão declara que todos os seres humanos foram criados de uma única alma. ${ }^{129} \mathrm{Um}$ hadith afirma que "a universa inteira é a família de Alá" e um outro diz que os humanos são "tão parecidos quanto os dentes de um pente". ${ }^{130}$ As escrituras da Fé bahá'ie declaram: "Todas os povos e nações são de uma única família, os filhos de um Pai, e devem ser um para o outro como irmãos e irmãs!". ${ }^{131}$

Ao respeito do conceito do valor alto da diversidade da família humana, certas passagens das escrituras reverenciadas Ihe dão muito apoio. Por exemplo, de acordo com o profeta Isaias, Israel deve ser "um terceiro parceiro com Egito e Assíria", que são todos abençoados por Deus -132 uma passagem que coloca a ênfase sobre o respeito de povos diferentes. O Alcorão dá elogios à diversidade da família humana, e afirma que a variedade de línguas e cores de pessoas é um dos sinais de Deus. ${ }^{133}$ Ele afirma também que todas as raças e tribos foram criadas

127 Malachi 2:10, em TANAKH. A New Translation of The Holy Scriptures According to the Traditional Hebrew Text. Philadelphia: The Jewish Publication Society, 1985 (tradução do autor).

128 Mateus 23:9, em THE HOLY BIBLE. Containing the Old and New Testaments: New Revised Standard Version. New York: Oxford University Press, 1989 (tradução do autor).

129 Alcorão 4:1, em ARBERRY, A. J. The Koran Interpreted. New York: Simon and Schuster, 1955 (tradução do autor).

130 Citado em WEERAMANTRY, C.G. Islamic Jurisprudence: An International Perspective. New York: St. Martin's Press, 1988. p. 133 (tradução do autor).

131 'ABDU'L-BAHÁ. Paris Talks: Addresses Given by 'Abdu'l-Bahá in Paris in 1911-1912. New Delhi: Bahá'í Publishing Trust, 1971. p. 140 (tradução do autor).

132 Isaias 19.24-25, em TANAKH. A New Translation of The Holy Scriptures According to the Traditional Hebrew Text. Philadelphia: The Jewish Publication Society, 1985 (tradução do autor).

133 Alcorão 30:21, em ARBERRY, A. J. The Koran Interpreted. New York: Simon and Schuster, 1955. 
por Deus para que elas possam conhecer os outros e colaborar umas com as outras. ${ }^{134}$ Ademais, as escrituras da fé bahá'ie dizem que o princípio da unidade da família humana nem ignora nem suprime

a diversidade de origens étnicas, de clima, de história, de língua e tradição, de pensamento e hábito, que diferenciam os povos e nações do mundo. Ele exige uma lealdade mais larga, uma aspiração maior do que alguma que tem animado a raça humana - o seu lema é unidade em diversidade. ${ }^{135}$

Além disso, as escrituras santas em algumas passagens mesmo prefiguram o conceito de medidas especiais, muitas vezes prescrevendo a prestação de uma atenção especial às necessidades dos pobres e de outros grupos desfavorecidos, como os estrangeiros e aderentes de crenças minoritárias - tudo isso apesar da história lamentável de persecuções de grupos desfavorecidos no nome de uma religião majoritária.

Por exemplo, o Bhagavad-Gita, uma escritura reverenciada do hinduísmo, declara que "Brahman-nirvana é ganhada pelos visionários que deliciam no bemestar de todos seres". ${ }^{136}$ As escrituras hebreias instruem os judeus a defender os direitos dos oprimidos e dos vulneráveis, os comandando: "fale em prol dos mudos, em prol dos direitos de todos os desfavorecidos. / Fale, julgue justamente, / Campeone os pobres e as pessoas carentes". ${ }^{137}$ Jesus diz, quanto às vítimas de discriminação ou persecução, o seguinte: "Bençoados sejam aqueles que são perseguidos para a causa de justiça, porque os seus é o reino do Céu”. ${ }^{138}$ Ele nos aconselha para ajudar aqueles que nós temos ferido, mesmo indo além do necessário para os compensar, o que é estreitamente justo, dizendo: “E se qualquer pessoa processe você perante os tribunais, e tire embora o seu casaco, permita-Ihe também tirar embora a sua capa". ${ }^{139}$ Paul nos aconselha: "Permita que nada seja feito para contenda ou vangloria; mas em humildade permita que

\footnotetext{
134 Alcorão 49:13, em ARBERRY, A. J. The Koran Interpreted. New York: Simon and Schuster, 1955.

135 EFFENDI, Shoghi. The World Order of Bahá'u'lláh: Selected Letters by Shoghi Effendi. 2. ed. rev. Wilmette, III.: Bahá'í Publishing Trust, 1974. p. 41-42 (tradução do autor).

136 Bhagavad-Gita 5:25, 12:4, THE BHAGAVAD GITA. Tradução de de Franklin Edgerton. Cambridge: Harvard University Press, 1972 (tradução do autor).

137 Provérbios 31.8-9, de TANAKH. A New Translation of The Holy Scriptures According to the Traditional Hebrew Text. Philadelphia: The Jewish Publication Society, 1985 (tradução do autor).

138 Mateus 5:10, de THE HOLY BIBLE. Containing the Old and New Testaments: New Revised Standard Version. New York: Oxford University Press, 1989 (tradução do autor).

139 Mateus 5:40, de THE HOLY BIBLE. Containing the Old and New Testaments: New Revised Standard Version. New York: Oxford University Press, 1989 (tradução do autor).
} 
cada um estime os outros melhor do que si mesmo". ${ }^{140}$ O Alcorão declara que a piedade verdadeira é de “dar os seus bens, qualquer acalentados, aos pais e aos órfãos, às pessoas carentes, ao viageiro, aos mendigos, e a resgatar os escravos". ${ }^{141}$ Ademais, o Alcorão diz que nós devemos preferir os outros acima de nós mesmos, dando louvores àqueles que amam "quaisquer que tem emigrado para eles", "preferindo os outros acima de si mesmos, mesmo se a pobreza seja a porção deles". ${ }^{142}$

As escrituras bahá'íes dizem que nós devemos "socorrer os despossuídos, e jamais reter" a nosso "favor de os destituídos". ${ }^{143}$ Elas também lecionam que nós devemos preferir o nosso irmão acima de nós mesmos. ${ }^{144}$ Especificamente falando de um tipo de ação afirmativa, as escrituras bahá'ies, que geralmente prescrevem o uso de eleições democráticas, contêm uma regra segundo a qual se há um empate em uma eleição, e um dos candidatos é um membro de um grupo minoritário, o minoritário tem que ser escolhido. ${ }^{145}$

Cabe enfatizar que os princípios de unidade em diversidade e de interdependência familiar dão forte apoio a ações afirmativas, não sendo baseados apenas em um conceito lógico de igualdade. Por contraste, eles insistem que todos os seres humanos são membros de um corpo único, e que se um membro deste corpo está doente, o corpo inteiro vai sofrer. Ademais, estes princípios colocam a ênfase sobre o valor positivo da diversidade, e, portanto, aprovariam medidas especiais visando aumentar a diversidade de profissões e empregos diferentes. Esta perspectiva ajudaria a resolver dúvidas sobre a legitimidade de tomar em conta a busca de diversidade. A abordagem é também baseada na compaixão e não em um conceito rígido e não emocional de igualdade formal. Ela não pode resolver todas as disputas sobre as ações afirmativas, mas pode iluminar estes debates.

No plano judicial, nós podemos interpretar ambiguidades nos tratados e outras fontes de direito internacional à luz destes princípios. ${ }^{146}$ Por exemplo, em

140 Philippians 2:3, de THE HOLY BIBLE. Containing the Old and New Testaments: New Revised Standard Version. New York: Oxford University Press, 1989 (tradução do autor).

141 Alcorão 2:172, de ARBERRY, A. J. The Koran Interpreted. New York: Simon and Schuster, 1955 (tradução do autor).

142 Alcorão 59:9, de ARBERRY, A. J. The Koran Interpreted. New York: Simon and Schuster, 1955 (tradução do autor).

143 BAHÁ'U'LLÁH. Gleanings from the Writings of Bahá'u'lláh. Tradução de Shoghi Effendi. 2. ed. rev. Wilmette, III.: Bahá'í Publishing Trust, 1976. p. 265 (tradução do autor).

144 Veja BAHÁ'U'LLÁH. Tablets of Bahá'u'lláh Revealed after the Kitáb-i-Aqdas. Tradução de Habib Taherzadeh. Haifa: Bahá'í World Centre, 1978. p. 71.

145 Veja EFFENDI, Shoghi. The Advent of Divine Justice. Wilmette, III.: Bahá'í Publishing Trust, 1966. p. 35.

146 Para uma explicação mais compreensiva de um método de interpretação levando em consideração estes princípios, veja geralmente LEPARD, Brian D. Rethinking Humanitarian Intervention: A Fresh Legal Approach 
decidindo quando ou se certa medida implementada de acordo com um tratado tal como CEDAW tenha alcançado a sua meta de estabelecer qualquer nível e tipo de igualdade, e portanto deve ser terminada, nós podemos tomar em conta o conceito da interdependência familiar. Particularmente, nós podemos reconhecer os ferimentos que podem continuar se uma população vulnerável é deixada sozinha cedo demais, e, portanto, nós devemos exigir provas certas de igualdade antes de terminar uma medida especial. Nós podemos também avaliar o grau de diversidade que tem sido realizado; o valor de alcançar um nível suficiente de diversidade, como valor importante em si mesmo, pode justificar a manutenção de medidas especiais. E o princípio de interdependência familiar daria apoio a interpretações de tratados favorecendo o reconhecimento de uma obrigação, e não somente uma permissão, de tomar tais medidas.

Os princípios da unidade em diversidade e da interdependência familiar podem também ajudar na identificação do direito internacional consuetudinário. Segundo a teoria clássica desta fonte, explicada acima, uma norma torna-se direito internacional consuetudinário quando os estados do mundo agem de uma maneira consistente com a norma (referido como "uma prática geral") e quando eles agem assim porque eles acreditam que eles têm uma obrigação jurídica de seguir esta prática (referido como opinio juris). No entanto, esta definição, recentemente reafirmada pela Comissão de Direito Internacional das NU, e aprovada pela Assembleia Geral das Nações Unidas, ${ }^{147}$ tem muitas fraquezas. Uma delas é que ela não faz referência às implicações éticas das normas em questão. Em vez disso, eu tenho desenvolvido uma nova teoria do direito internacional consuetudinário segundo a qual uma norma se torna uma norma de direito internacional consuetudinário quando os estados do mundo, em geral, acreditam que seria desejável, agora mesmo ou no futuro próximo, ter um princípio jurídico ou uma regra jurídica exigindo, permitindo, ou proibindo certa conduta. De acordo com a minha teoria, uma prática geral não é necessária, mas pode fornecer prova de uma tal crença. Além disso, se nós temos dúvidas concernentes às crenças de estados, nós podemos considerar o efeito de uma norma proposta sobre a realização de princípios éticos fundamentais. ${ }^{148}$

Based on Fundamental Ethical Principles in International Law and World Religions. Pennsylvania: Penn State University Press, 2002. p. 102-103; 113-18.

147 Veja NAÇõES UNIDAS. Assembleia Geral das Nações Unidas. Resolution adopted by the General Assembly on 20 December 2018, 73/203: Identification of customary international law. A/RES/73/203. Annex, Conclusion 2 ("To determine the existence and content of a rule of customary international law, it is necessary to ascertain whether there is a general practice that is accepted as law (opinio juris))" ("Para determinar a existência e o conteúdo de uma regra do direito internacional consuetudinário, é preciso verificar se há uma prática geral que é aceita como lei (opinio juris)") (tradução do autor).

148 Veja LEPARD, Brian D. Customary International Law. A New Theory with Practical Applications. New York: Cambridge University Press, 2010. p. 8. 
Sem resolver a questão definitivamente aqui, a prevalência de medidas especiais para proteger populações vulneráveis na legislação interna de muitos países, acompanhada pelos tratados e declarações internacionais que eu revi aqui, são provas de uma crença, apesar das polêmicas ao redor do assunto, na necessidade de tais medidas no mundo atual que sofre tanto de desigualdade. Ademais, se existem dúvidas sobre a existência de um consensus e uma prática compartilhados o suficiente, o fato de que as medidas especiais para proteger populações vulneráveis são relacionadas aos princípios da unidade em diversidade e da interdependência familiar pode apoiar o reconhecimento de um opinio juris em prol delas. Isso pode sustentar a conclusão de que uma obrigação de tomar certo tipo de medida especial é atualmente uma parte do direito internacional consuetudinário.

\section{Conclusão}

Para concluir, eu tenho tentado avaliar a legalidade e a ética de medidas especiais sob o direito internacional e as suas relevâncias às polêmicas atuais sobre este assunto. Eu tenho proposto uma nova abordagem a este problema baseada em princípios éticos fundamentais encontrados dentro de instrumentos contemporâneos de direito internacional bem como escrituras santas das religiões do mundo. Espero que uma tal abordagem possa abrir a porta a sintonizar opiniões diferentes entre membros de governos e o público geral. Esta abordagem sugere que é essencial mudar preconceitos e atitudes perante membros de populações vulneráveis e transformá-las para uma visão de unidade em diversidade, sustentando também a ideia de interdependência familiar. Ademais, em apoiando esta visão com extratos de passagens santas, a abordagem exibe o potencial de atrair a atenção de pessoas que se descrevem como adeptas de religiões mundiais diversas.

The legality and ethics of special measures to protect vulnerable populations under international law Abstract: Currently, in many countries around the world, controversy is surging over special measures
implemented by law to promote the social and economic advancement of members of various vulnerable
populations - measures often called "affirmative action". These measures may take the form of quotas
or special preferences seeking to increase opportunities for members of these populations in the
areas of employment or education, for example, to the same level as other members of society.
This article seeks to explore the legal and ethical implications of the norms in international law on
national policies concerning affirmative actions. Before embarking on this exploration, it reviews some
notions of equality at the conceptual level. Next, the article briefly explores the history of the treatment
of vulnerable populations in society and the approach taken by international law to that history. It
investigates some fundamental concepts developed in contemporary international law related to the 
adoption of special measures to protect vulnerable populations. At the same time, the article identifies some issues that are not resolved by international law according to a traditional interpretation. Next, the article elaborates a legal and ethical theory of how to interpret these norms of international law and resolve these remaining issues. This theory is based on the concept of "unity in diversity", which finds support in contemporary international law as well as in the revered scriptures of many world religions and beliefs. Finally, the article applies this theory to reach some conclusions about the legality and ethics under international law of national measures aimed at protecting vulnerable populations. The article does not purport to resolve the controversy that is raging around this issue, but the hope is that the approach it proposes can help us achieve a deeper understanding of the problem.

Keywords: Vulnerable populations. Special measures. Affirmative action. Racial minorities. Women. International law. Equality. Ethics. Religious scriptures.

Contents: Introduction - 1 Important Concepts of Equality - 2 The Debate on Affirmative Action in Light of These Concepts - $\mathbf{3}$ The History of the Treatment of Vulnerable Populations in Light of These Concepts - 4 The Evolution of the Approach Adopted by International Law to the Treatment of Vulnerable Populations - 5 The General Approach of Sources of International Law to the Legality and Ethics of Special Measures to Protect Vulnerable Populations - $\mathbf{6}$ Remaining Issues - 7 Towards a New Theory of the Legality and Ethics of Special Measures to Protect the Rights of Vulnerable Populations under International Law - Conclusion - References

\section{Referências}

‘ABDU'L-BAHÁ. Paris Talks: Addresses Given by ‘Abdu'I-Bahá in Paris in 1911-1912. New Delhi: Bahá'í Publishing Trust, 1971.

ARBERRY, A. J. The Koran Interpreted. New York: Simon and Schuster, 1955.

ASSEMBLEIA NACIONAL CONSTITUINTE FRANCESA. Declaração dos Direitos do Homem e do Cidadão de 1789. Disponivel em: http://pfdc.pgr.mpf.mp.br/atuacao-e-conteudos-de-apoio/legislacao/direitoshumanos/declar_dir_homem_cidadao.pdf. Acesso em: 29 maio 2020.

BAHÁ'U'LLÁH. Gleanings from the Writings of Bahá'u'lláh. Tradução de Shoghi Effendi. 2. ed. rev. Wilmette, III.: Bahá'í Publishing Trust, 1976.

BAHÁ'U'LLÁH. Tablets of Bahá'u'lláh Revealed after the Kitáb-i-Aqdas. Tradução de Habib Taherzadeh. Haifa: Bahá'í World Centre, 1978.

BECKMAN, James A. Introduction. In: BECKMAN, James A. Controversies in Affirmative Action: Historical Dimensions. Santa Barbara, Ca.: Praeger, 2014. v. 1.

BRASIL. Constituição da República Federativa do Brasil de 1988. Brasília, 1988. Disponível em: http:// www.planalto.gov.br/ccivil_03/Constituicao/Constituicao.htm. Acesso em: 29 maio 2020.

CAHN, Steven M. (Ed.). The Affirmative Action Debate. London: Routledge, 1995.

EFFENDI, Shoghi. The Advent of Divine Justice. Wilmette, III.: Bahá'í Publishing Trust, 1966.

EFFENDI, Shoghi. The World Order of Bahá'u'lláh: Selected Letters by Shoghi Effendi. 2. ed. rev. Wilmette, III.: Bahá'í Publishing Trust, 1974.

ESTADOS UNIDOS DA AMÉRICA. Constituição dos Estados Unidos. Disponível em: https://www.archives. gov/founding-docs/constitution. Acesso em: 29 maio 2020. 
ESTADOS UNIDOS DA AMÉRICA. Departamento de Trabalho dos Estados Unidos. Ação Afirmativa. Disponivel em: https://www.dol.gov/general/topic/hiring/affirmativeact. Acesso em: 29 maio 2020.

ESTADOS UNIDOS DA AMÉRICA. Suprema Corte dos Estados Unidos. Regents of the Univ. of Calif. $v$. Bakke, 438 U.S. 265. Decidido em 28.06.1978.

EUROPA. Conselho da Europa. Convenção para a Proteção dos Direitos do Homem e das Liberdades Fundamentais. Roma, 4.11.1950. Disponível em: https://www.echr.coe.int/Documents/Convention_ POR.pdf. Acesso em: 29 maio 2020.

GINSBERG, Ruth Bader. Remarks on the Value of Diversity: International Affirmative Action. Institut d'Etudes Politiques, Paris, France, 17 de julho de 2009. In: GINSBERG, Ruth Bader; HARTNETT, Mary; WILLIAMS, Wendy W. My Own Words. New York: Simon \& Schuster, 2016.

IMPÉRIO BRITÂNICO; FRANÇA; ITÁLIA; JAPÃO; ESTADOS UNIDOS; POLÔNIA. Tratado sobre as minorias entre os poderes principais aliados e associados (o Império britânico, França, Itália, Japão e os Estados Unidos) e Polônia, firmado em Versailles (28junho 1919). Disponível em: http://www.forost.ungarischesinstitut.de/pdf/19190628-3.pdf. Acesso em: 29 maio 2020.

ÍNDIA. Constituição da Índia. Disponível em: https://www.india.gov.in/sites/upload_files/npi/files/ coi_part_full.pdf. Acesso em: 29 maio 2020.

KELSEN, Hans. What is Justice? Justice, Law and Politics in the Mirror of Science. Berkeley and Los Angeles: University of California Press, 1957.

LEPARD, Brian D. Customary International Law: A New Theory with Practical Applications. New York: Cambridge University Press, 2010.

LEPARD, Brian D. Rethinking Humanitarian Intervention: A Fresh Legal Approach Based on Fundamental Ethical Principles in International Law and World Religions. Pennsylvania: Penn State University Press, 2002.

NAÇÕES UNIDAS. Assembleia Geral das Nações Unidas. Carta das Nações Unidas. 26 jun. 1945. Disponivel em: https://www.oas.org/dil/port/1945\%20Carta\%20das\%20Na\%C3\%A7\%C3\%B5es\%20 Unidas.pdf. Acesso em: 29 maio 2020.

NAÇÕES UNIDAS. Assembleia Geral das Nações Unidas. Convenção sobre a Eliminação de Todas as Formas de Discriminação contra a Mulher (CEDAW). 1979. Disponivel em: http://www.pge.sp.gov.br/ centrodeestudos/bibliotecavirtual/instrumentos/discrimulher.htm. Acesso em: 29 maio 2020.

NAÇÕES UNIDAS. Assembleia Geral das Nações Unidas. Convenção sobre a Eliminação de Todas Formas de Discriminação Racial. 21 dez. 1965. Disponível em: https://www2.camara.leg.br/atividade-legislativa/ comissoes/comissoes-permanentes/cdhm/comite-brasileiro-de-direitos-humanos-e-politica-externa/ ConvIntElimTodForDiscRac.html. Acesso em: 29 maio 2020.

NAÇÕES UNIDAS. Assembleia Geral das Nações Unidas. Declaração das Nações Unidas sobre os Direitos dos Povos Indigenas. 13 set. 2007. Disponivel em: https://pib.socioambiental.org/files/file/ PIB_institucional/DECLARACAO_DAS_NACOES_UNIDAS_SOBRE_OS_DIREITOS_DOS_POVOS_INDiGENAS. pdf. Acesso em: 29 maio 2020.

NAÇÕES UNIDAS. Assembleia Geral das Nações Unidas. Declaração sobre os Direitos das Pessoas Pertencentes a Minorias Nacionais ou Étnicas, Religiosas e Linguísticas. Aprovada pela resolução 47/135 da Assembleia Geral da ONU de 18 de dezembro de 1992. Disponivel em: http://www.direitoshumanos.usp.br/index.php/ Preven\%C3\%A7\%C3\%A3o-contra-a-Discrimina\%C3\%A7\%C3\%A3o-e-Prote\%C3\%A7\%C3\%A3o-das-Minorias/ declaracao-sobre-os-direitos-das-pessoas-pertencentes-a-minorias-nacionais-ou-etnicas-religiosas-elinguisticas.html. Acesso em: 29 maio 2020. 
NAÇÕES UNIDAS. Assembleia Geral das Nações Unidas. Declaração Universal dos Direitos Humanos ("DUDH"). G.A. Res. 217A (III) (1948). Disponivel em: https://www.ohchr.org/EN/UDHR/Documents/ UDHR_Translations/por.pdf. Acesso em: 29 maio 2020.

NAÇÕES UNIDAS. Assembleia Geral das Nações Unidas. Pacto Internacional sobre Direitos Civis e Políticos (PIDCP). 1966. Disponivel em: http://www.planalto.gov.br/ccivil_03/decreto/1990-1994/ D0592.htm. Acesso em: 29 maio 2020.

NAÇÕES UNIDAS. Assembleia Geral das Nações Unidas. Pacto Internacional sobre Direitos Econômicos, Sociais e Culturais (PIDESC). 1966. Disponível em: http://www.planalto.gov.br/ccivil_03/ decreto/1990-1994/D0591.htm. Acesso em: 29 maio 2020.

NAÇÕES UNIDAS. Assembleia Geral das Nações Unidas. Resolution adopted by the General Assembly on 20 December 2018, 73/203: Identification of customary international law. A/RES/73/203.

NAÇÕES UNIDAS. Comitê dos Direitos Humanos. Comentário Geral No. 18. U.N. Doc. HRI/GEN/1/Ver.4 (2000). Disponivel em: https://tbinternet.ohchr.org/_layouts/15/treatybodyexternal/Download.aspx?s ymbolno=INT\%2fCCPR\%2fGEC\%2f6622\&Lang=en. Acesso em: 29 maio 2020.

NAÇÕES UNIDAS. Comitê sobre os Direitos Econômicos, Sociais e Culturais. Comentário Geral No. 13. “The right to education (article 13 of the Covenant)". U.N. Doc. E/C.12/1999/10 (1999).

NAÇÕES UNIDAS. Committee on the Elimination of Discrimination Against Women. General Recommendation 25: Article 4, paragraph 1, of the Convention (temporary special measures). 30th session, 2004. Disponível em: https://tbinternet.ohchr.org/Treaties/CEDAW/Shared\%20Documents/1_ Global/INT_CEDAW_GEC_3733_E.pdf. Acesso em: 29 maio 2020.

NAÇÕES UNIDAS. Committee on the Elimination of Racial Discrimination. General Recommendation No. 32. The Meaning and Scope of Special Measures in the International Convention on the Elimination of All forms of Racial Discrimination. U.N. Doc. CERD/C/GC/32 (2009). Disponivel em: https://tbinternet. ohchr.org/_layouts/15/treatybodyexternal/Download.aspx?symbolno=CERD\%2fC\%2fGC\%2f32\&Lang= en. Acesso em: 29 maio 2020.

NAÇÕES UNIDAS. Convenção para a Prevenção e a Repressão do Crime de Genocídio. 9 dez. 1948. Disponivel em: https://www.oas.org/dil/port/1948\%20Conven\%C3\%A7\%C3\%A30\%20sobre\%20a\%20 Preven\%C3\%A7\%C3\%A30\%20e\%20Puni\%C3\%A7\%C3\%A30\%20do\%20Crime\%20de\%20Genoc\%C3\%Addio. pdf. Acesso em: 29 maio 2020.

NAÇÕES UNIDAS. Convenção sobre os Direitos da Criança. 1989. Disponível em: http://www.planalto. gov.br/ccivil_03/decreto/1990-1994/D99710.htm. Acesso em: 29 maio 2020.

NAÇÕES UNIDAS. Convenção sobre os Direitos de Pessoas com Deficiência. Disponível em: http:// www.planalto.gov.br/ccivil_03/_Ato2007-2010/2009/Decreto/D6949.htm. Acesso em: 29 maio 2020.

NAÇÕES UNIDAS. Declaração sobre a Raça e os Preconceitos Raciais. Conferência Geral da Organização das Nações Unidas para a Educação, a Ciência e a Cultura, reunida em Paris em sua 20ำ reunião, em 27 de novembro de 1978. Disponível em: http://dhnet.org.br/direitos/sip/onu/discrimina/dec78.htm. Acesso em: 29 maio 2020.

NAÇÕES UNIDAS. Estatuto da Corte Internacional de Justiça. 1945. Disponível em: http://www. direitoshumanos.usp.br/index.php/Corte-Internacional-de-Justi\%C3\%A7a/estatuto-da-corte-internacionalde-justica.html. Acesso em: 29 maio 2020.

NUSSBAUM, Arthur. A Concise History of the Law of Nations. New York: The Macmillan Company, 1954.

OS TREZE ESTADOS UNIDOS DA AMÉRICA. Declaração de Independência dos Estados Unidos, 04 de julho de 1776. Disponivel em: https://www.archives.gov/founding-docs/declaration-transcript. Acesso em: 29 maio 2020. 
SKRENTNY, John David. The Ironies of Affirmative Action: Politics, Culture, and Justice in America. Chicago \& London: The University of Chicago Press, 1996.

SOCIEDADE DAS NAÇÕES. Corte Permanente de Justiça. Minority Schools in Albania, Advisory Opinion of 6 April 1935, P.C.I.J. Series A/B. Judgments, Orders and Advisory Opinios, No. 64, 1935.

SOCIEDADE DAS NAÇÕES. Pacto da Sociedade das Nações. 1919. Disponível em: http://dhnet.org.br/ direitos/anthist/his1919.htm. Acesso em: 29 maio 2020.

SUÁREZ, Francisco. Selections from Three Works of Francisco Suárez. Tradução de Gwladys L. Williams, Ammi Brown, e John Waldron, com certas revisões por Henry Davis, S.J. Oxford: Clarendon Press; London: Humphrey Milford, 1944. v. 2.

TANAKH. A New Translation of The Holy Scriptures According to the Traditional Hebrew Text. Philadelphia: The Jewish Publication Society, 1985.

THE BHAGAVAD GITA. Tradução de de Franklin Edgerton. Cambridge: Harvard University Press, 1972.

THE HOLY BIBLE. Containing the Old and New Testaments: New Revised Standard Version. New York: Oxford University Press, 1989.

THORNBERRY, Patrick. International Law and the Rights of Minorities. Oxford: Clarendon Press, 1991.

UNIÃO EUROPEIA. Carta dos Direitos Fundamentais da União Europeia (2000). Jornal Oficial das Comunidades Europeias, 2000/C 364/01, 18 dez. 2000. Disponível em: http://europarl.europa.eu/ charter/pdf/text_pt.pdf. Acesso em: 29 maio 2020.

UNITED NATIONS. Prevention of Discrimination - The Concept and Practice of Affirmative Action (Final report). E/CN.4/Sub.2/2002/21. Commission on Human Rights, 17 June 2002. ("Relatório do Repórter Especial").

WEERAMANTRY, C.G. Islamic Jurisprudence: An International Perspective. New York: St. Martin's Press, 1988.

WILSON, Woodrow. President Woodrow Wilson's Fourteen Points. 8 jan. 1918. Disponível em: https:// avalon.law.yale.edu/20th_century/wilson14.asp. Acesso em: 29 maio 2020.

Informação bibliográfica deste texto, conforme a NBR 6023:2018 da Associação Brasileira de Normas Técnicas (ABNT):

LEPARD, Brian D. A legalidade e a ética de medidas especiais para proteger populações vulneráveis sob o direito internacional. Direitos Fundamentais \& Justiça, Belo Horizonte, ano 14, n. 42, p. 113-157, jan./jun. 2020.

Recebido em: 13.05.2020

Aprovado em: 25.05.2020

Cota Convite 